خليفة بن محمد الفتحي داوود عبدالملك الحدابي وجيهة ثابت العاني ميراح سعود

المجلد الرابع عشر العدد (49) 2021م

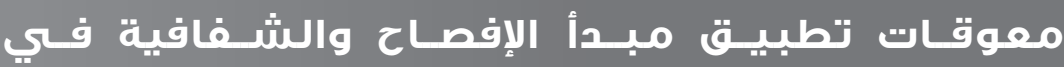

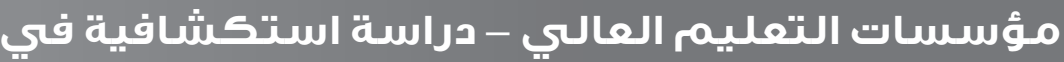

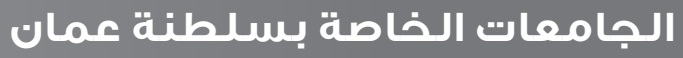

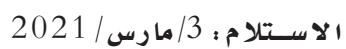

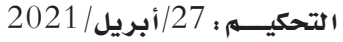

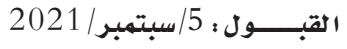

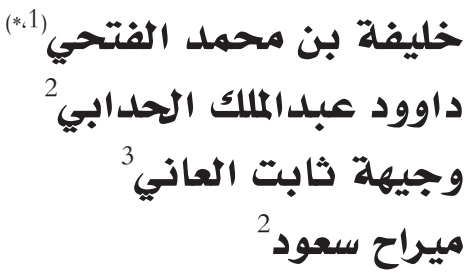

(c) 2021 University of Science and Technology, Yemen. This articlecan be distributed under the terms of the Creative Commons Attribution License, which permits unrestricted use, distribution, and reproduction in any medium, provided the original author and source are credited.

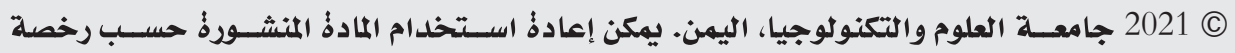
مؤسسة المشاع الإبداعي شريطة الاستشهاد بالمؤلف والمجلة. 
معوقات تطبيق مبدأ الإفصاح والشفافية في مؤسسات التعليمم العالي

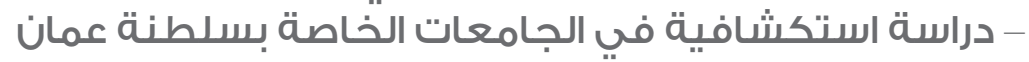

\section{الملخص: ت تصدف:}

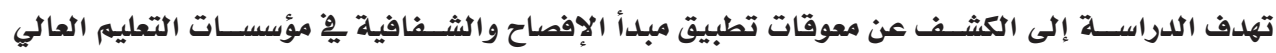

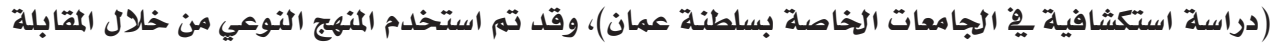

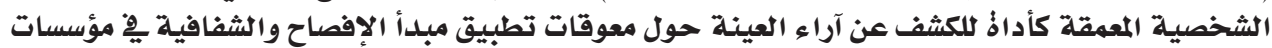

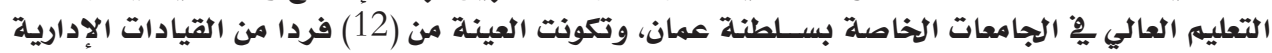

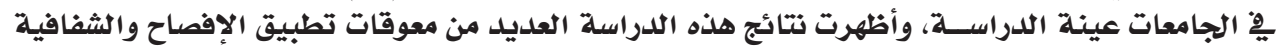

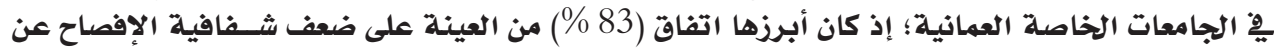

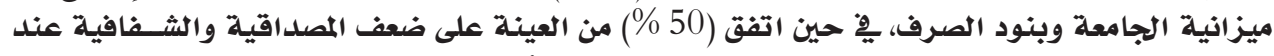

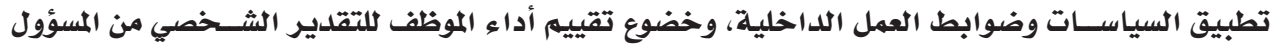

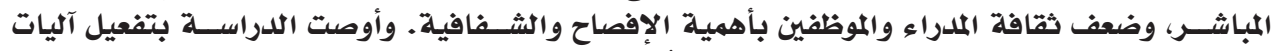

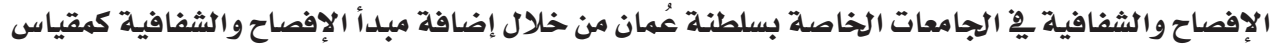

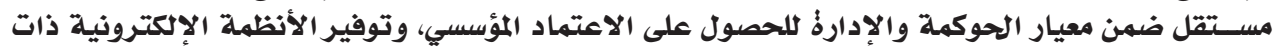
الخلدمات والوظائف المتكاملة. الكلمات المفتاحية : معوقات، مبدأ الإفصاح والشفافية، الجامعات الخاصة، سلطنة عُمان. 
خليفة بن محمد الفتحي داوود عبدالملك الحدابي وجيهة ثابت العاني ميراح سعود

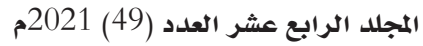

\title{
Obstacles to Applying the Principle of Disclosure and Transparency in Higher Education Institutions: An Exploratory Study in Private Universities in the Sultanate of Oman
}

\begin{abstract}
:
The study aimed to explore the obstacles to applying the principle of disclosure and transparency in higher education institutions in private universities in the Sultanate of Oman. The qualitative method was used through in-depth interview as a tool to reveal the opinions of the study sample about the obstacles to applying the principle of disclosure and transparency in private universities, Oman. The sample consisted of (12) individuals from the administrative leaders in the universities under study. The study results reported a number of obstacles to the application of disclosure and transparency in Omani private universities, where $(83 \%)$ of the sample agreed that there was weak disclosure transparency in the university's budget and the spending items. In addition, (50\%) of the sample agreed that there was weakness of credibility and transparency when applying policies, internal work controls, subjective evaluation of the employee's performance by his direct manager, and weak awareness of the importance of disclosure and transparency among managers. Therefore, the study recommended activating disclosure and transparency mechanisms in private universities in Oman by adding the principle of disclosure and transparency as an independent measure within the standard of governance and management to obtain institutional accreditation, and by providing electronic systems with integrated services and functions.
\end{abstract}

Keywords: obstacles, the principle of disclosure and transparency, private universities, the Sultanate of Oman. 


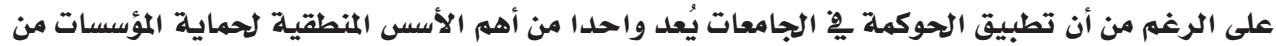

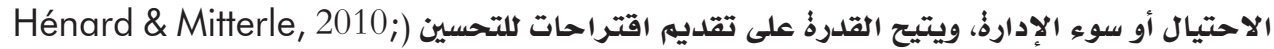

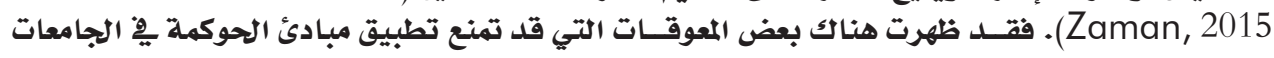

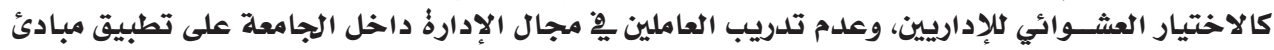

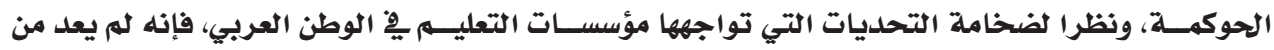

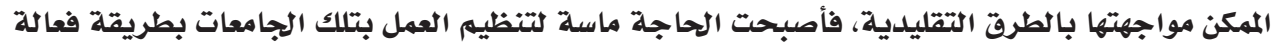

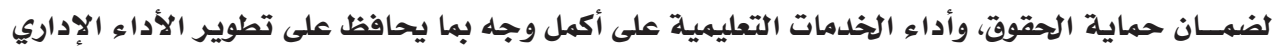

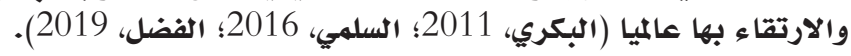

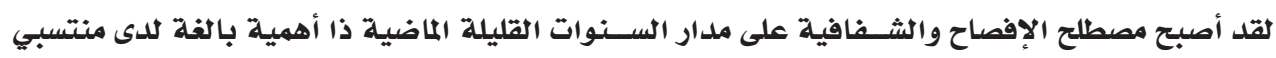

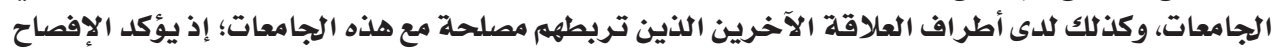

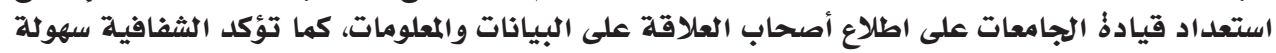

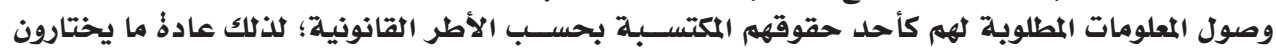

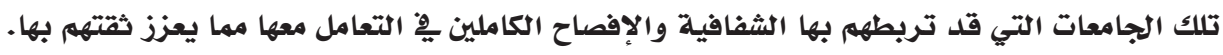

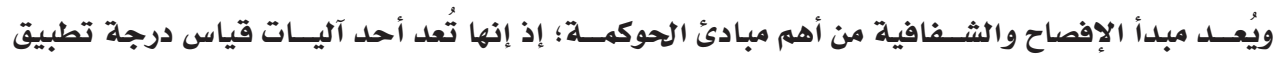

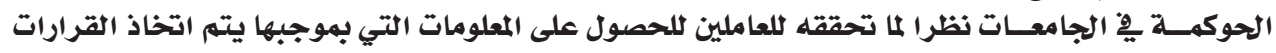

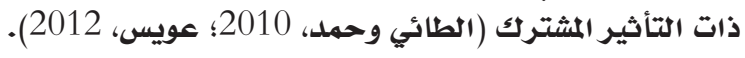

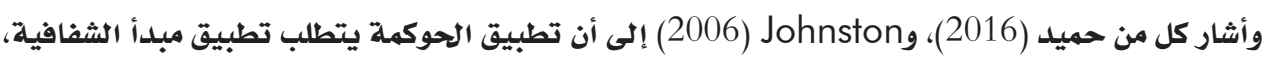

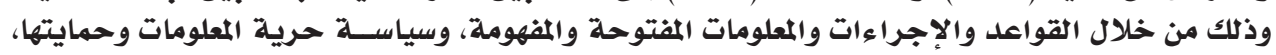

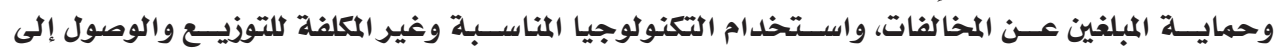

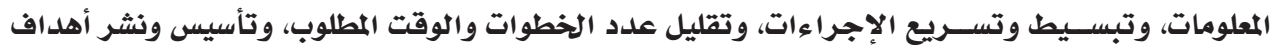

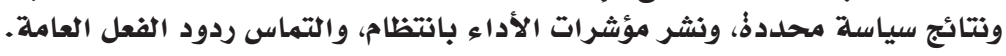

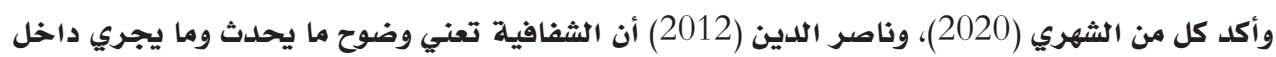

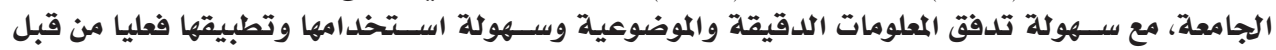

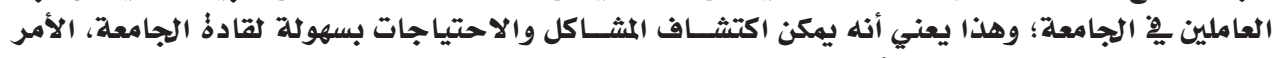

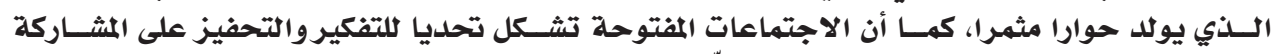

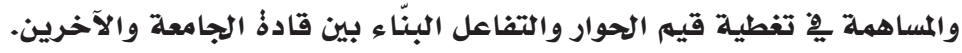

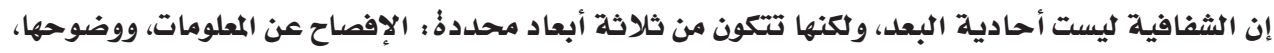

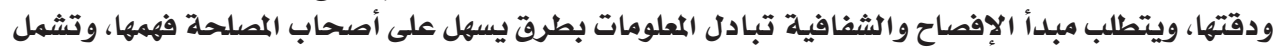

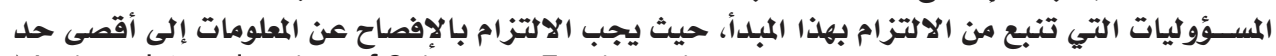

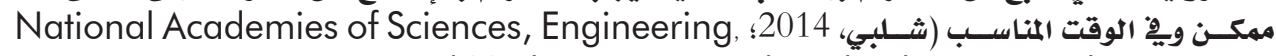
.(and Medicine, 2017; Schnackenberg \& Tomlinson, 2016

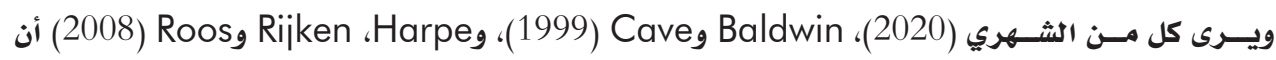
مبدأ الشـفافية يجب أن يشتهل على وجود تشريع شامل وواضح، يسهل فيه الوصول إلى الوثائق المتعلقة بالعملية التشريعية.

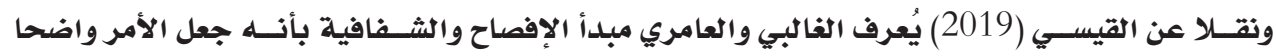

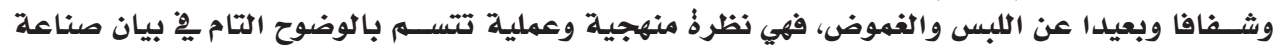

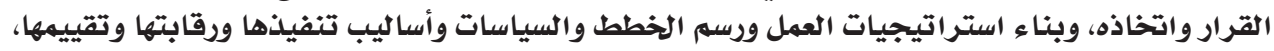

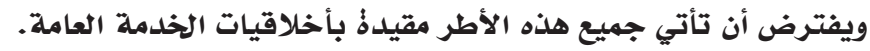


خليفة بن محمد الفتحي داوود عبدالملك الحدابي وجيهة ثابت العاني ميراح سعود

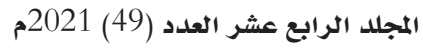

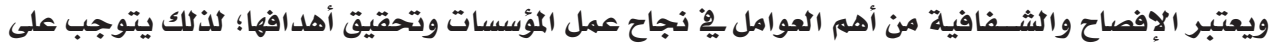

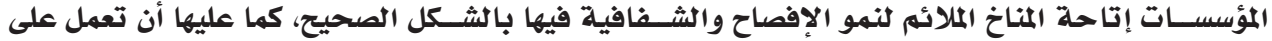

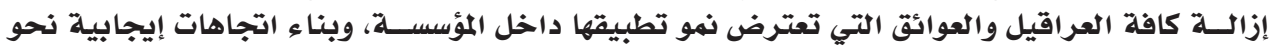
ممارستها (الشهري، 2020).

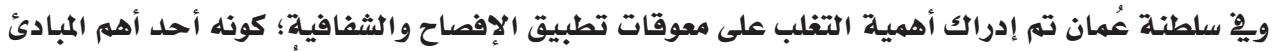

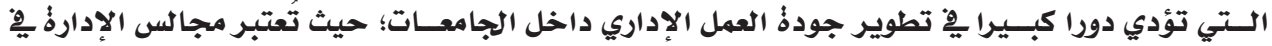

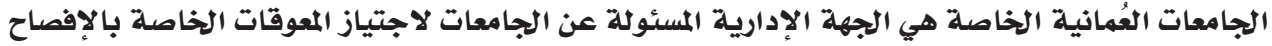

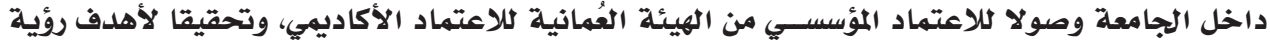

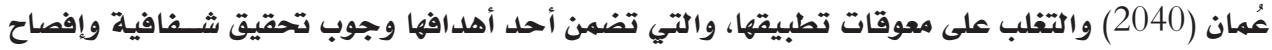

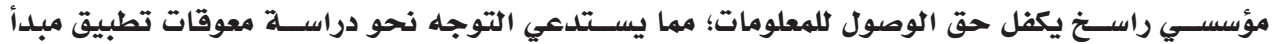

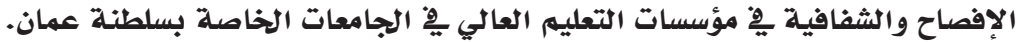

مفهوم الإفصاح والشفافية :

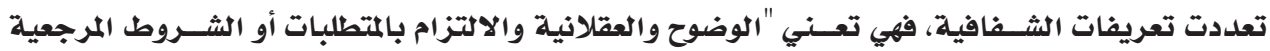

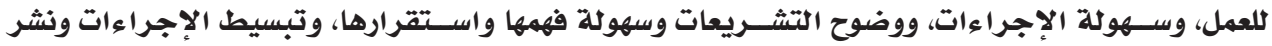

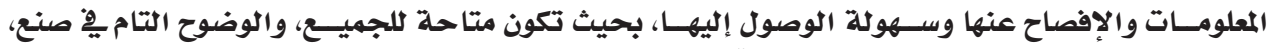
واتخاذ القرارات، ورسم الخطط عنهات والسياسات" (عثمان، 2014، 171).

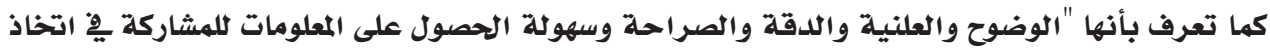

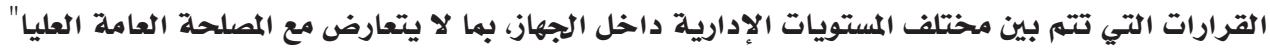

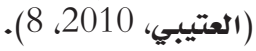

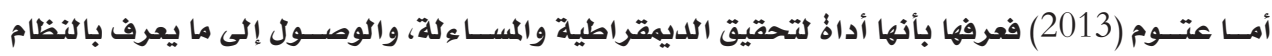

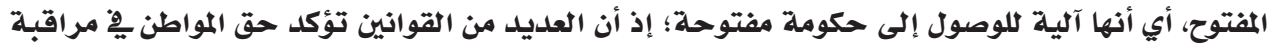

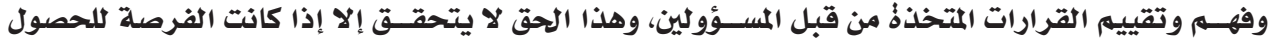

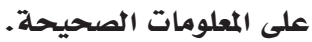
كما يعرفها السـبيعي (2011، 19) بأنها "الطريقة النزيهة يْ عمل الأثثـياء التي تمكن الناس من معرفة ما تقوم به بالضبط". كما تعرف بأنها :

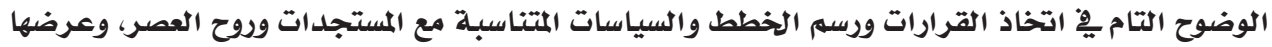

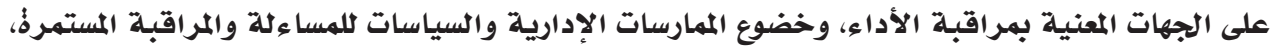

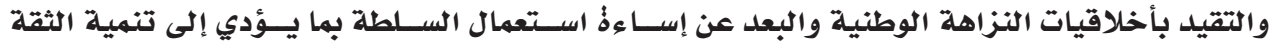

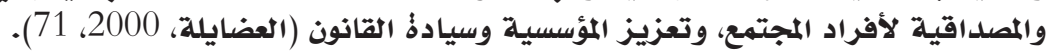
ووفقا لتعريف برنامج الأمم المتحدةُ الإنهائي فإن الشفافية هي :

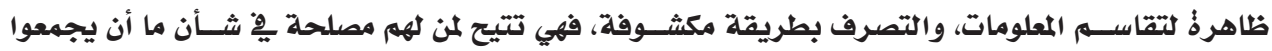

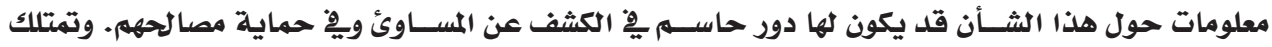

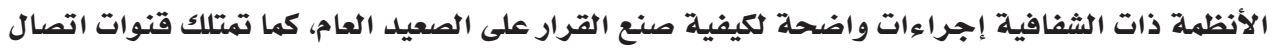

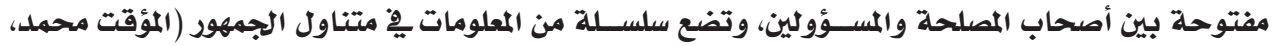

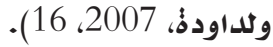




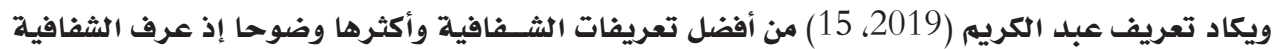

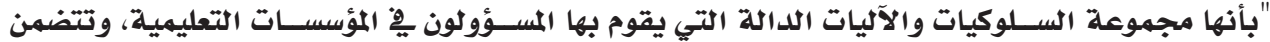

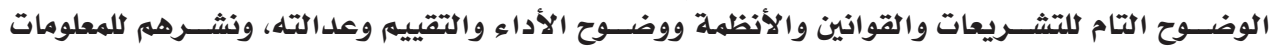

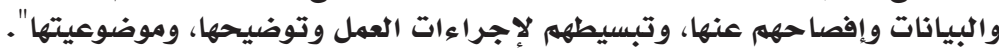

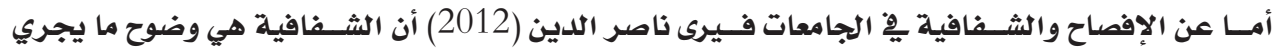

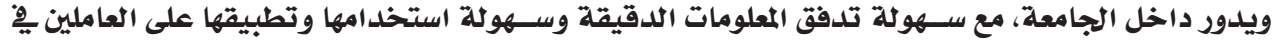

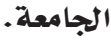

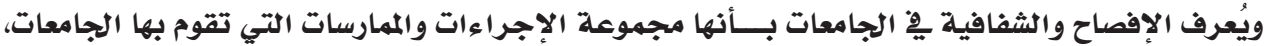

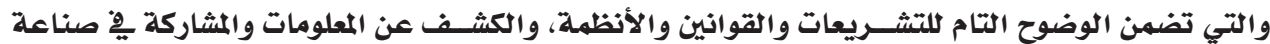
القرار (الشهري، 2020).

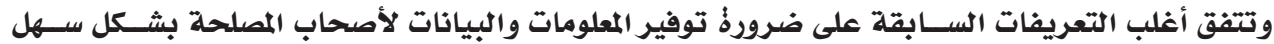

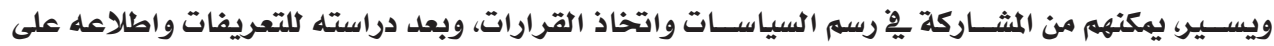

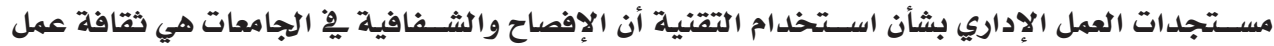

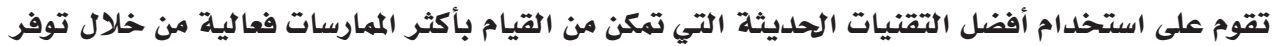

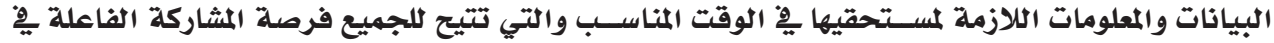

تحقيق أهداف الجامعة. متطلبات مبدأ الإفصاح والشفافية : يشـير الجرواني (2012) إلى أن هنالك العديد من المتطلبات الأساسـية يجب توفرها لتطبيق الشفافية يِّية

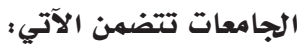

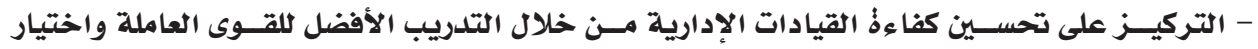

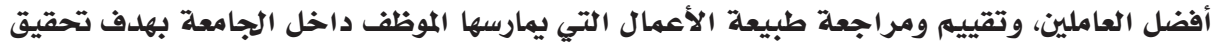
الاستقرار الوظيفي.

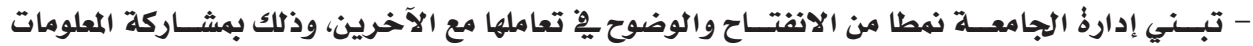

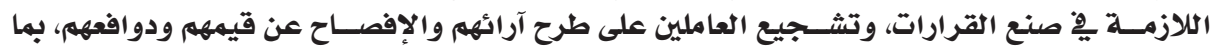
يؤدي إلى درجة عالية من الثقة المتبادلة بين الطرائ الثرفين.

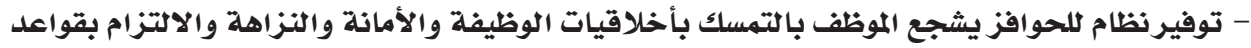
العمل ونظمهـ. - تبــني إجراءات محلددذُ لضمـــان إمكانية النزاهلة والمســـاءلة وتوفير الإجــراءات التأديبية الفعالة

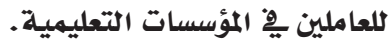

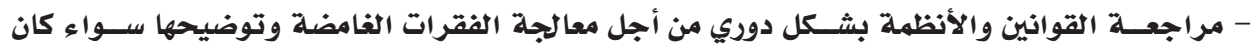

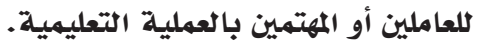

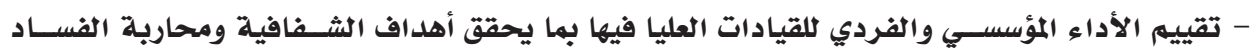

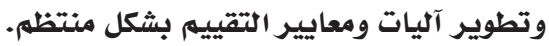

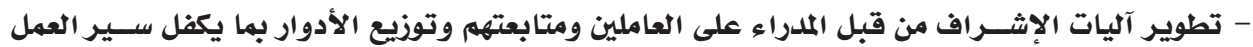
بوضوح وسهولة وإشعارهم بالاستقرار الوظيفي.

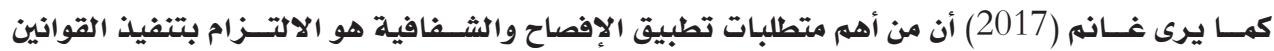

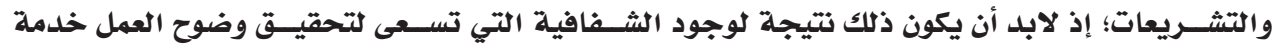




$$
\text { خليفة بن محمد الفتحي داوود عبدالملك الحدابي وجيهة ثابت العاني ميراح سعود المجلد العدابع (49) 2021م }
$$

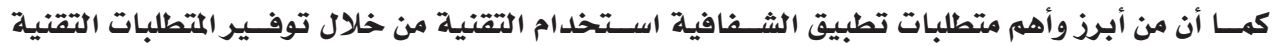

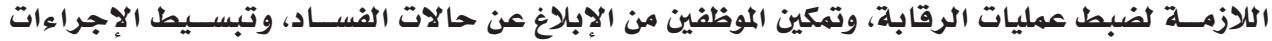

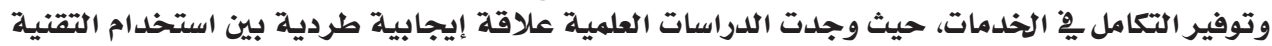

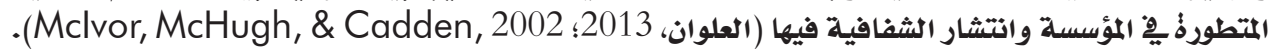

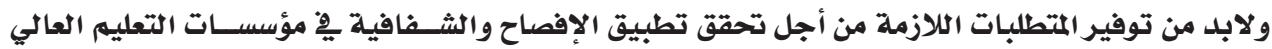

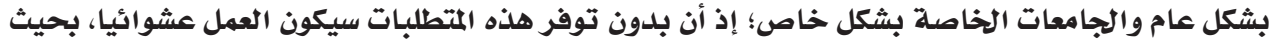

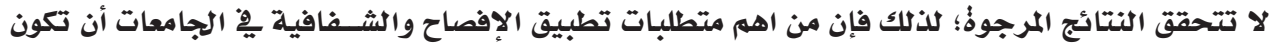

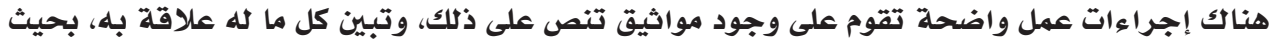

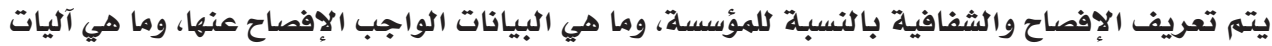

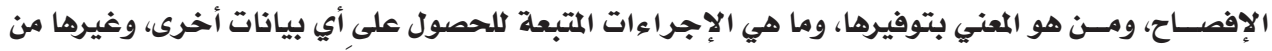

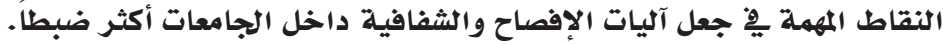

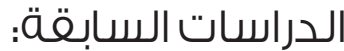

سيتم استعراض العديل من الدراسات السابقة على النحو الآتي:

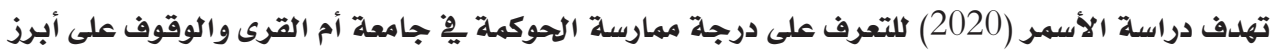

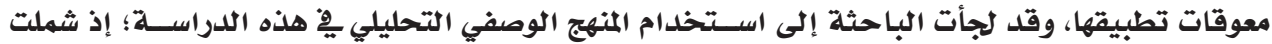

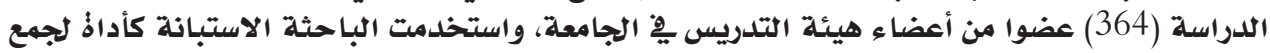

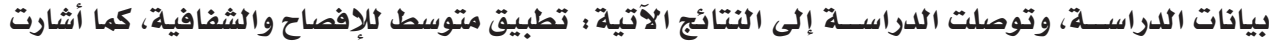

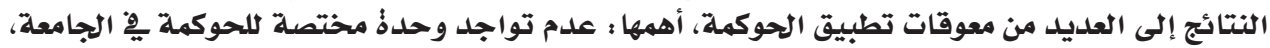

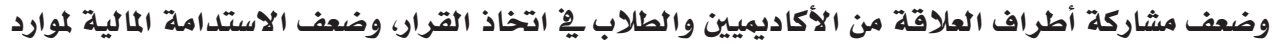

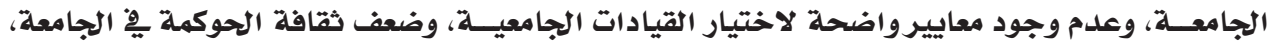

وغيرها من المعوقات العديدة.

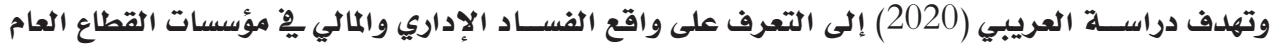

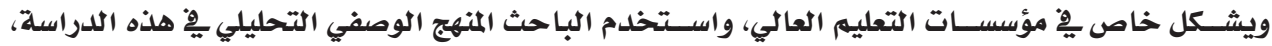

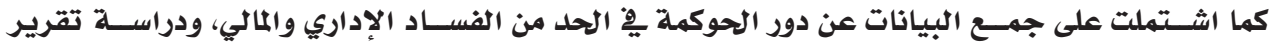

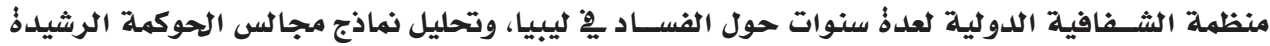

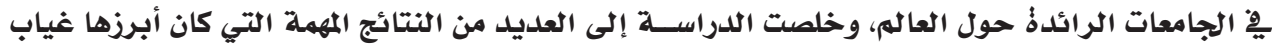

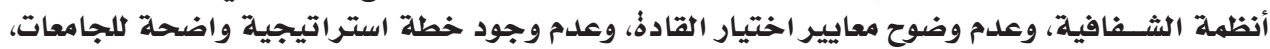

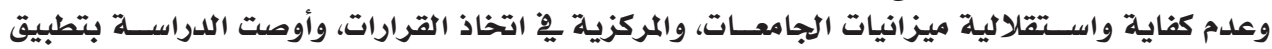

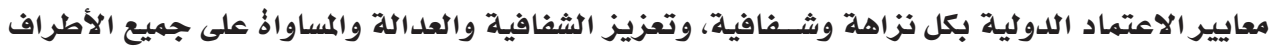
المعنية دون تحيز داخل الجامعات.

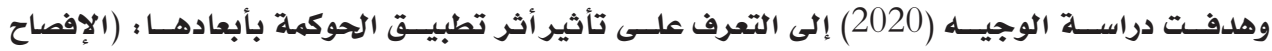

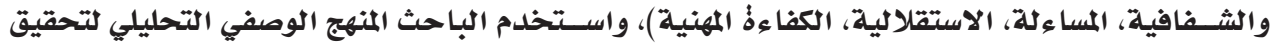

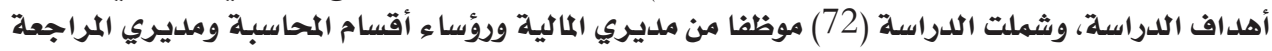

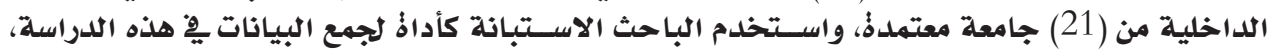

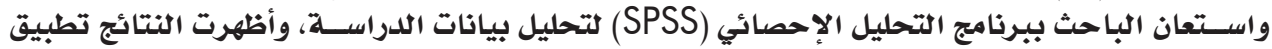

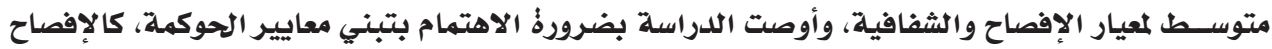

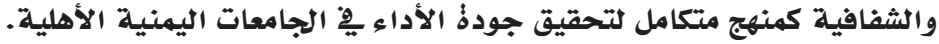

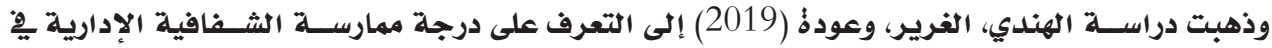

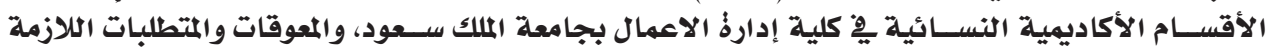




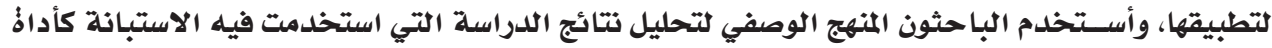

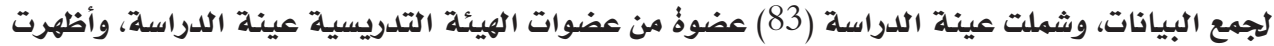

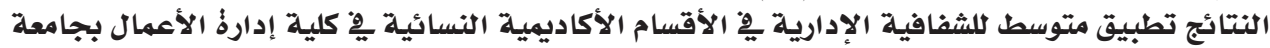

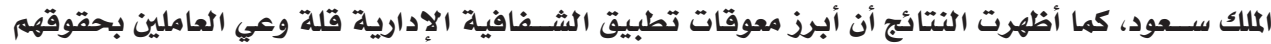

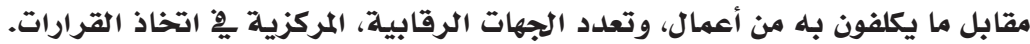

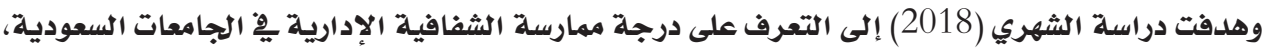

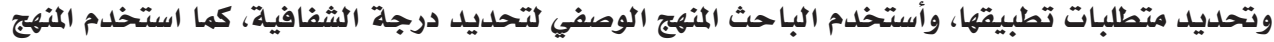

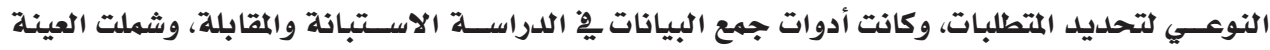

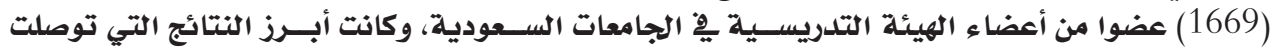

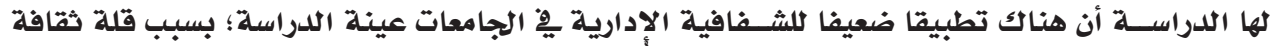

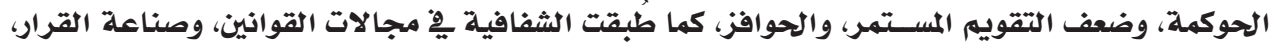

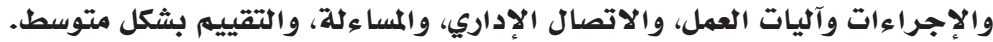

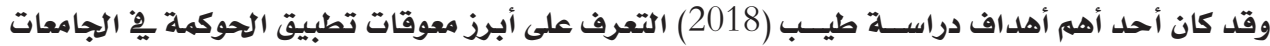

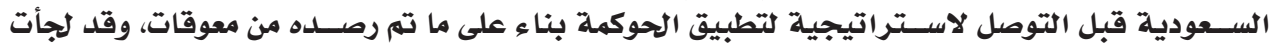

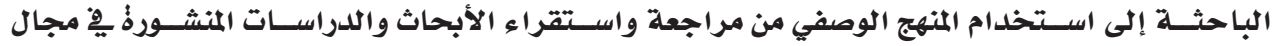

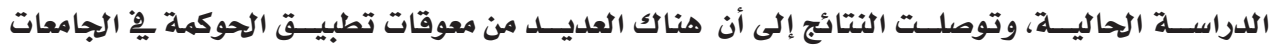

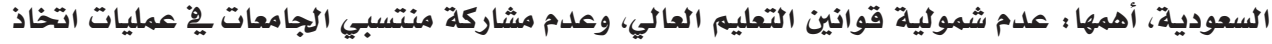

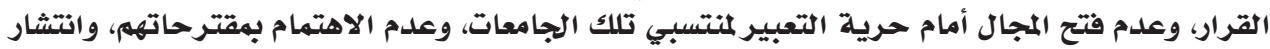

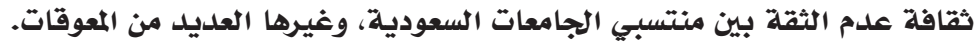

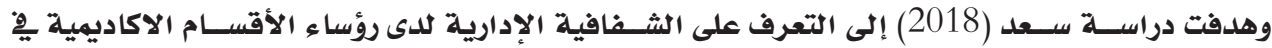

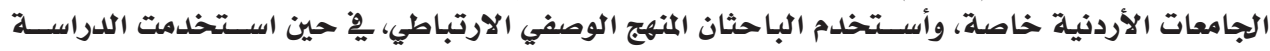

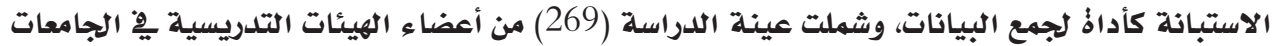

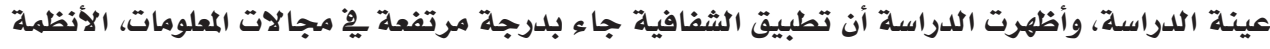

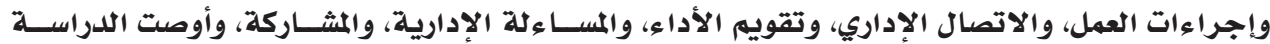

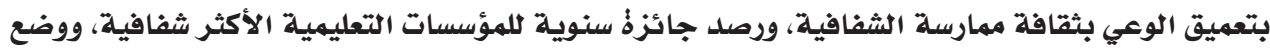
إستراتيجية ملزمة بتطبيق الوعافة ممارسة الشفافية.

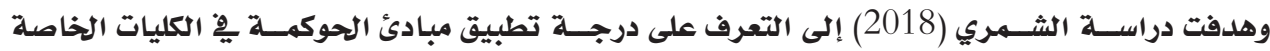

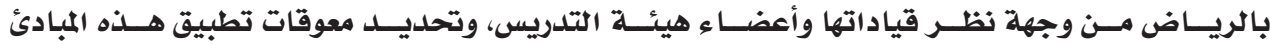

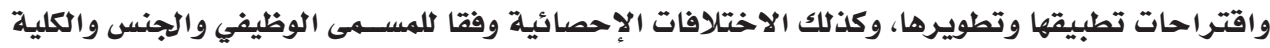

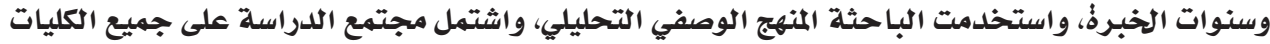

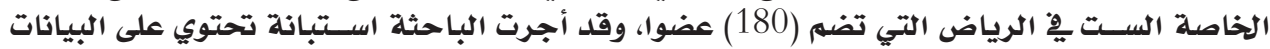

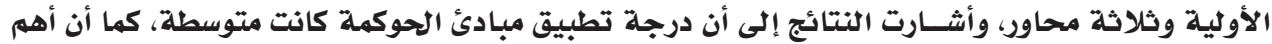

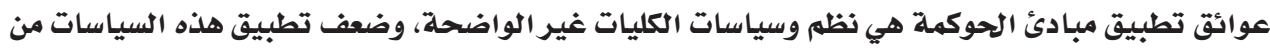

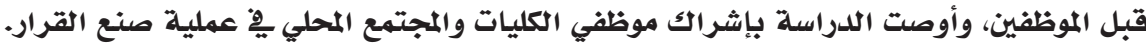

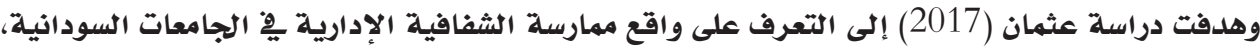

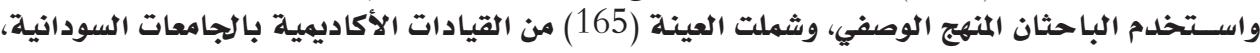

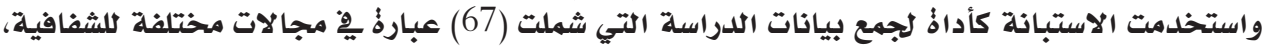

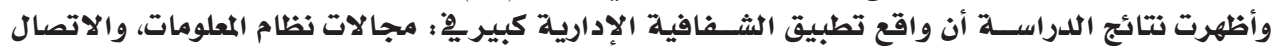

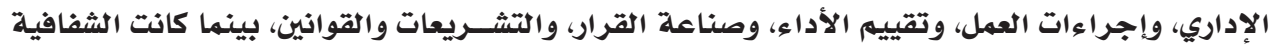

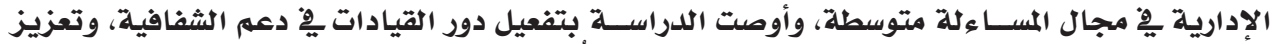
الالتزام بالشفافية الإدارية من خلال الالتحاق بلدورات تُعنى بممارسات الثفيل دور الثفافية. 
خليفة بن محمد الفتحي داوود عبدالملك الحدابي وجيهة ثابت العاني ميراح سعود

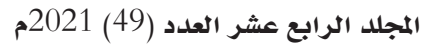

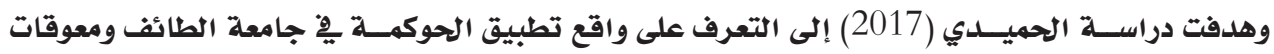

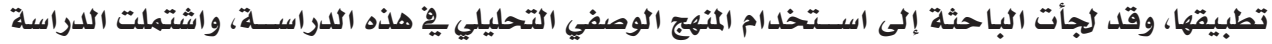

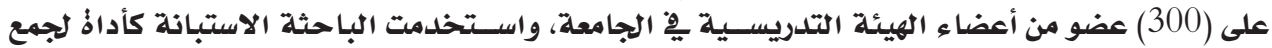

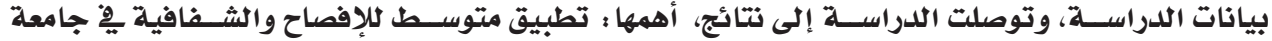

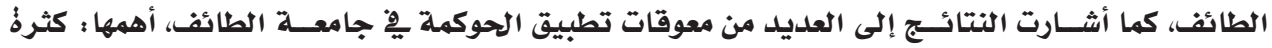

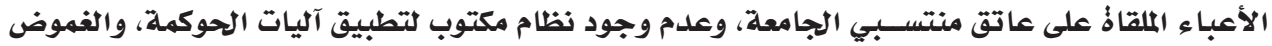

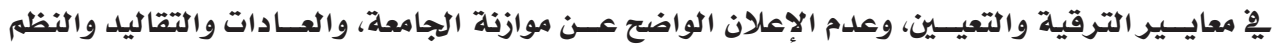

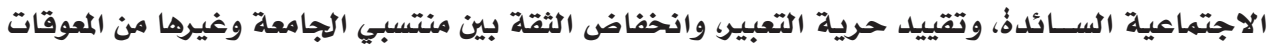
العديدة.

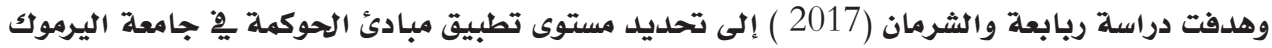

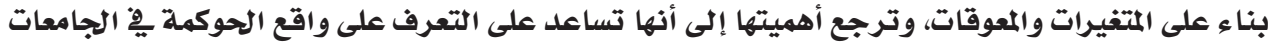

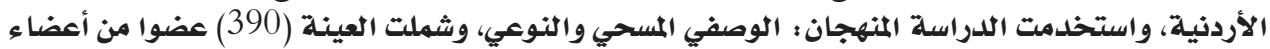

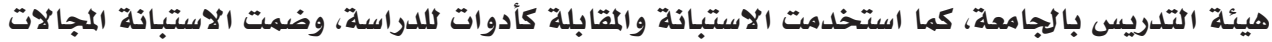

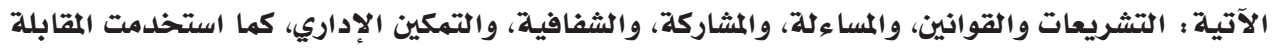

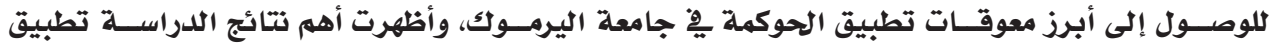

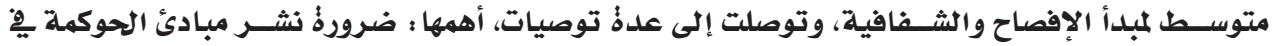

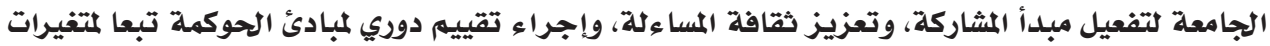
كل مرحلة.

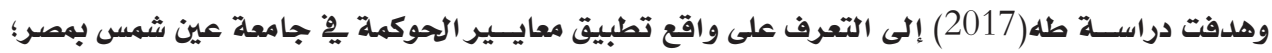

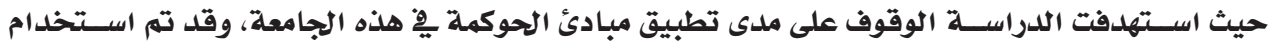

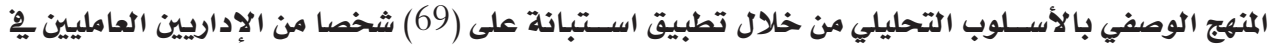

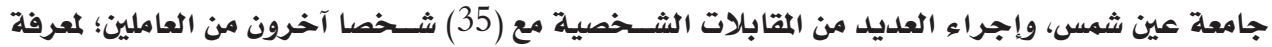

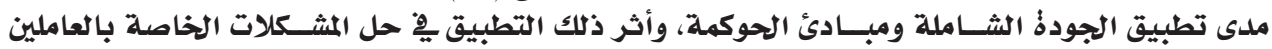

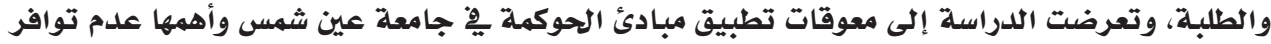

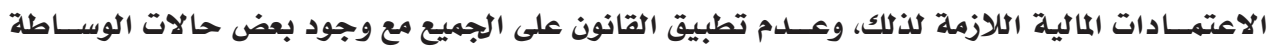

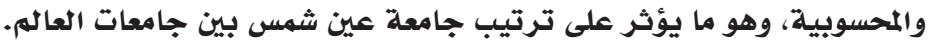

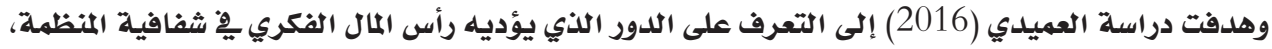

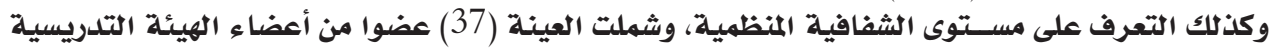

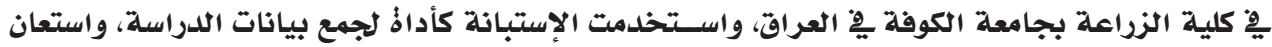

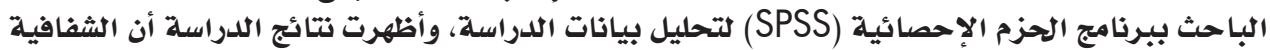

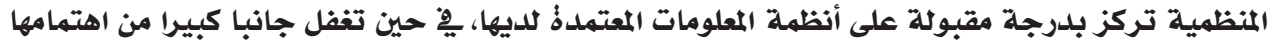

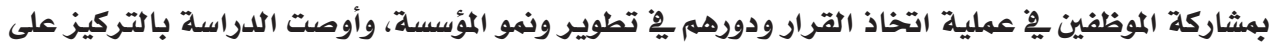

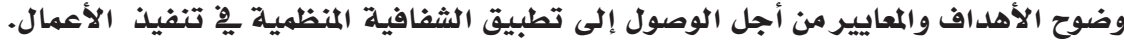

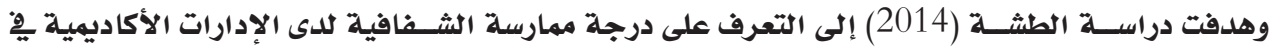

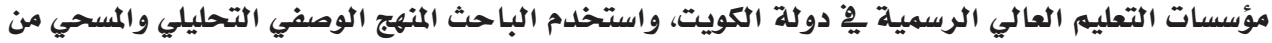

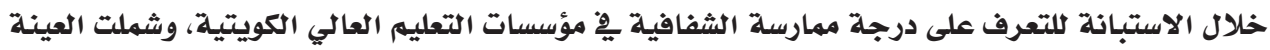

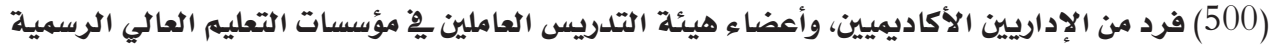

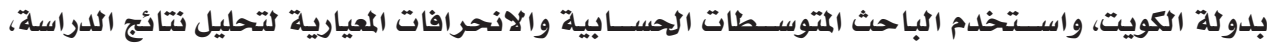

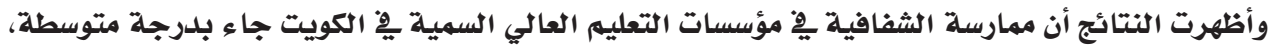

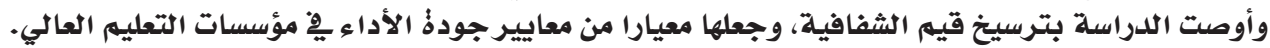




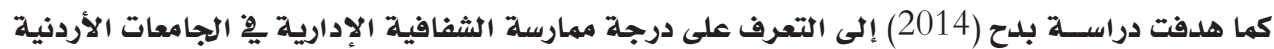

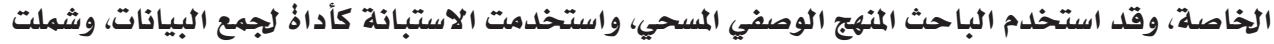

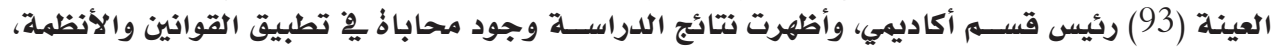

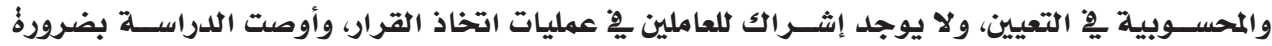

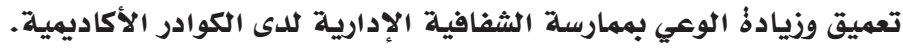

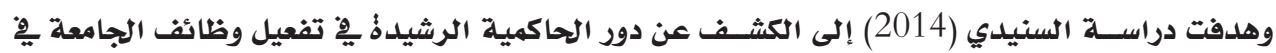

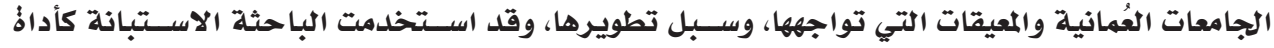

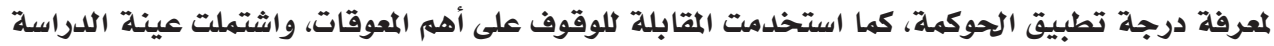

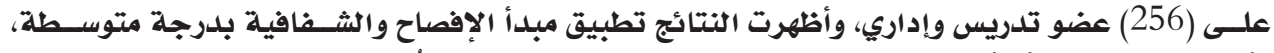

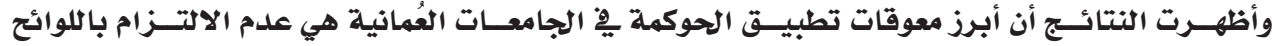

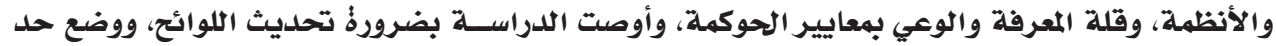
كلاستثناءات، وتوزيع المهام، والصلاحيات والوات بشكل، واضح، ونشرها.

\section{التعليق على الدراسات السابقة:}

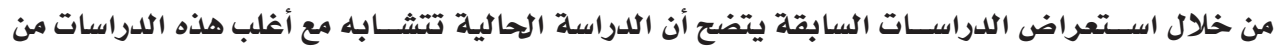

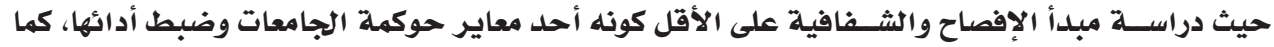

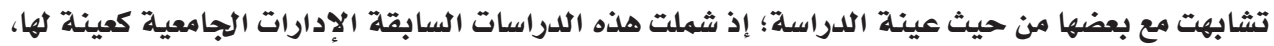

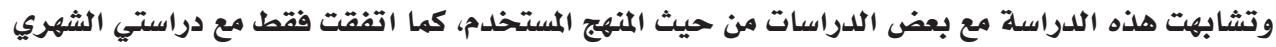

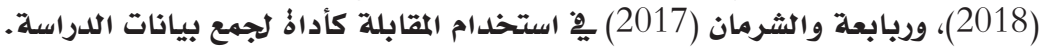

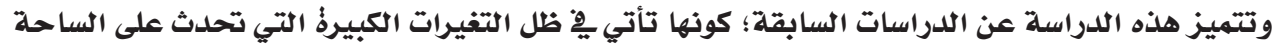

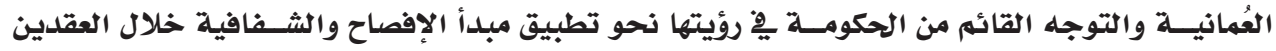

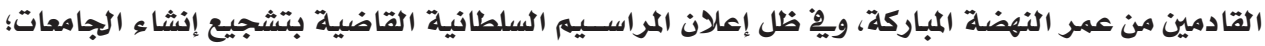

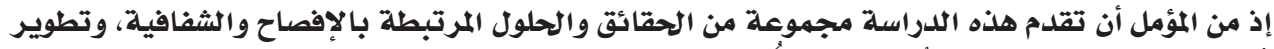

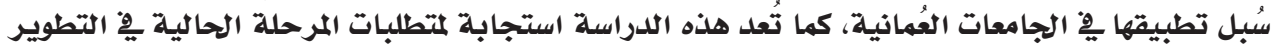

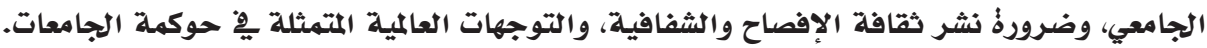

\section{ملثكلة الدراسة:}

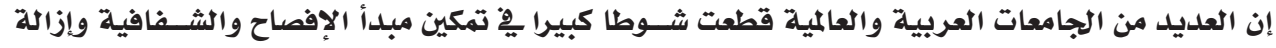

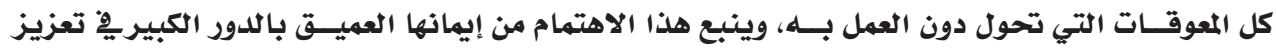

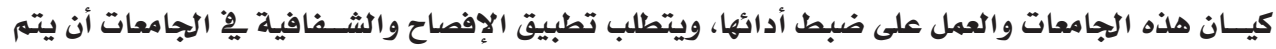

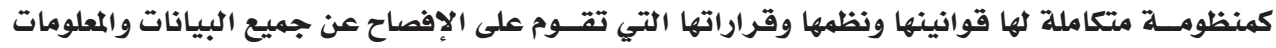

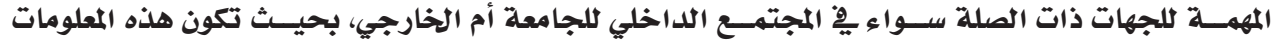

شفافة وصحيحة وتخلم المستهدف استهل المهافا ستواء حقيقيا.

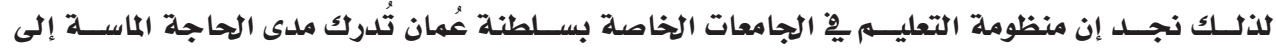

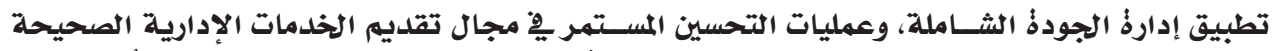

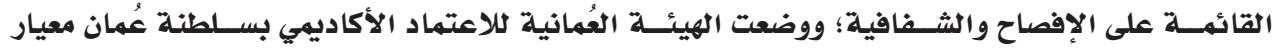

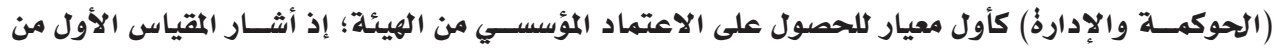

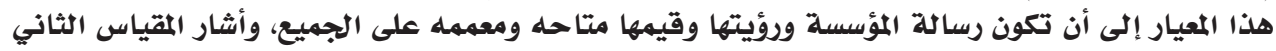

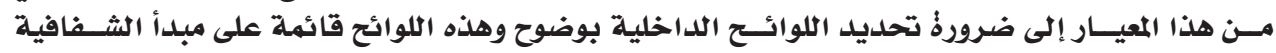

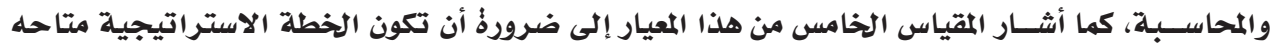

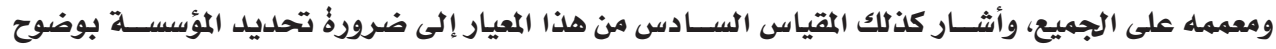


خليفة بن محمد الفتحي داوود عبدالملك الحدابي وجيهة ثابت العاني ميراح سعود

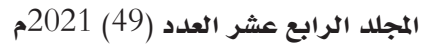

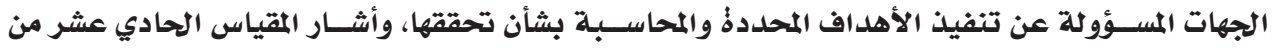

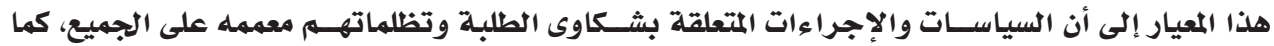

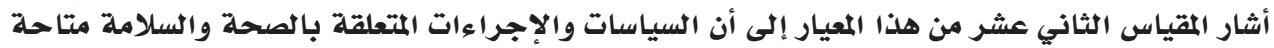

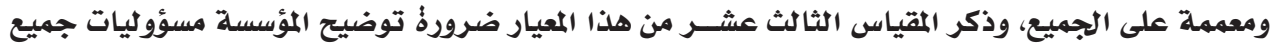

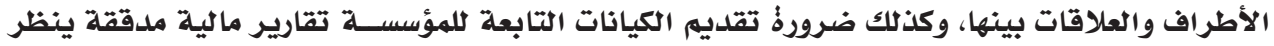

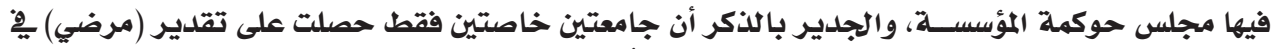

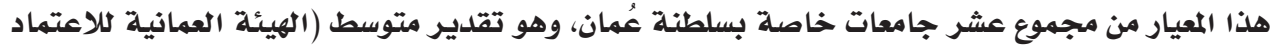

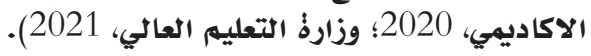

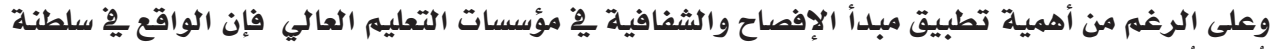

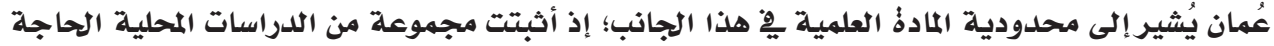

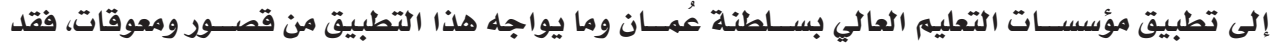

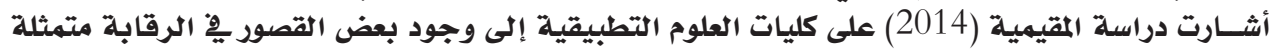

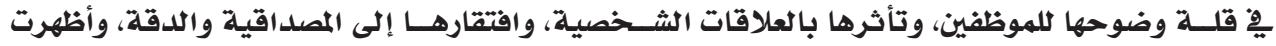

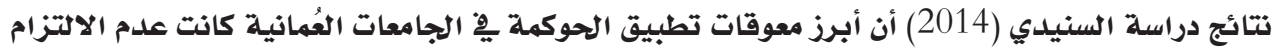

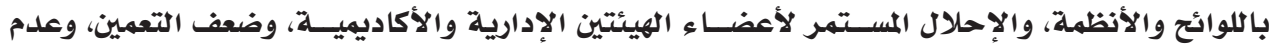

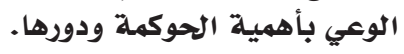

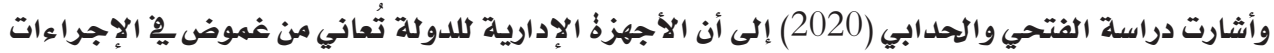

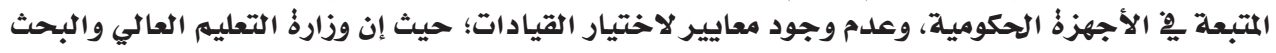

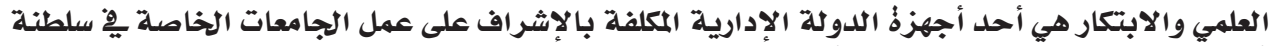

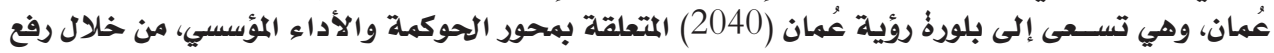

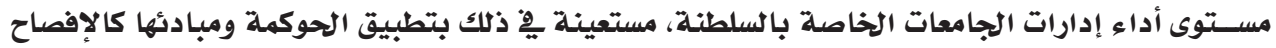

والشفافية.

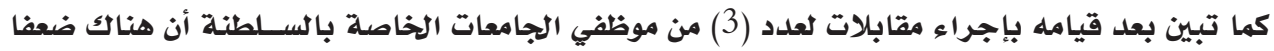

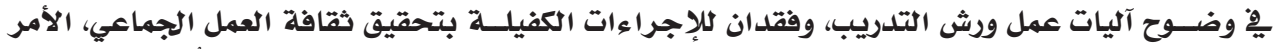

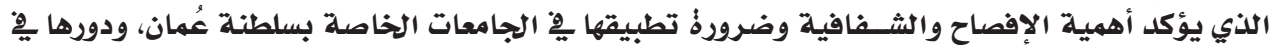

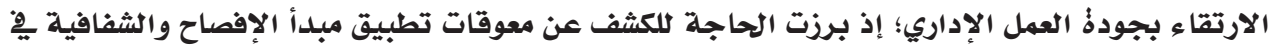

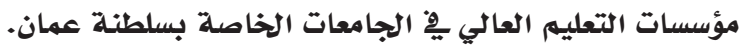
أسئلة الدراسة:

مِِّ ضوء مشكلة الدراسة تم وضع السؤال الآتي:

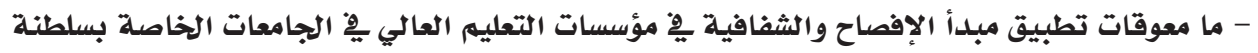

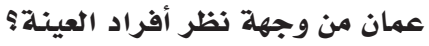

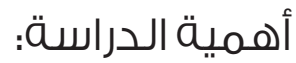

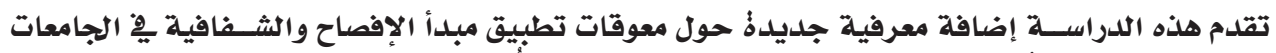

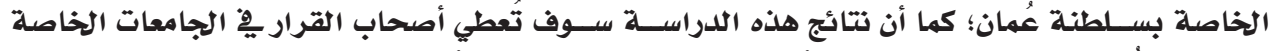

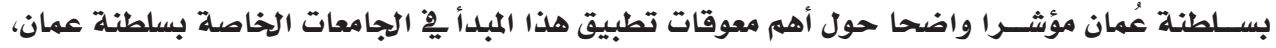

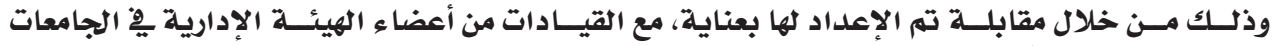

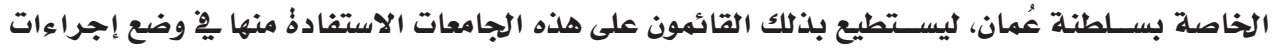

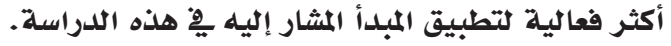




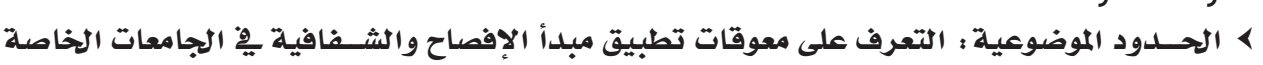

$$
\text { بسلطنة عمدان. }
$$

> الحلدود المكانية : الجامعات الخاصة بسلطنة عمان، لاسيما لجامعتي صحار والبريمي.

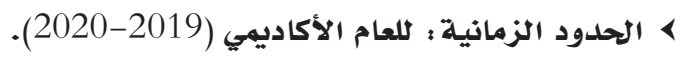

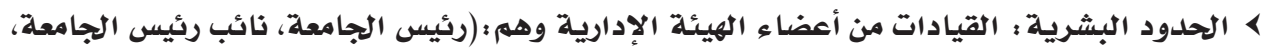

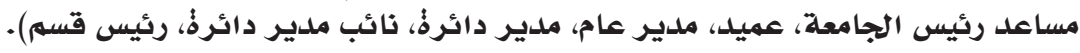

$$
\text { مصطلحات الدراسة: }
$$

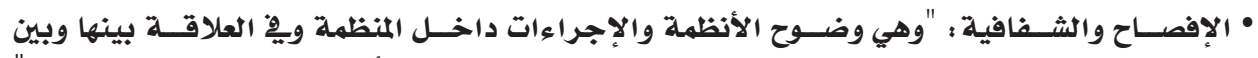

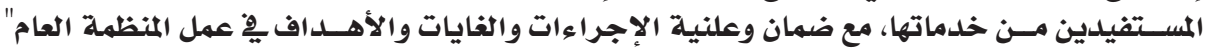

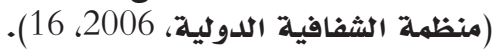

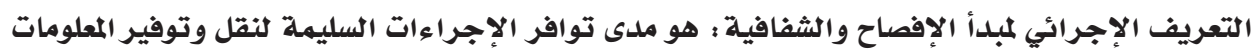

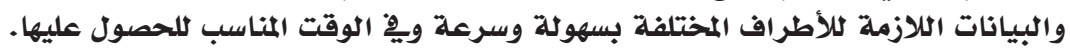

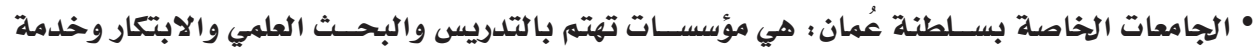

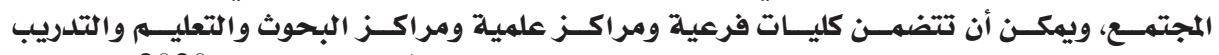

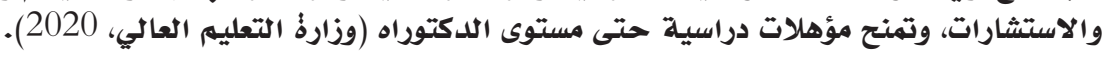

$$
\text { منهج الدراسة الدراسة وإجـراءاتهـا: }
$$

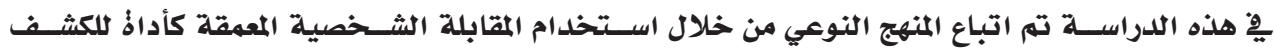

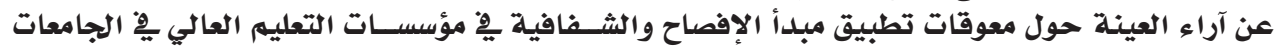

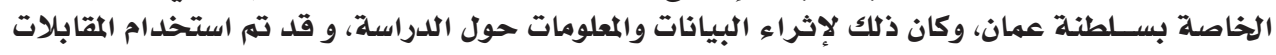

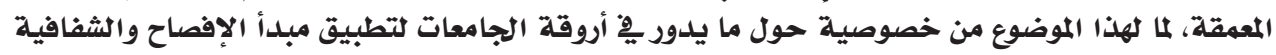

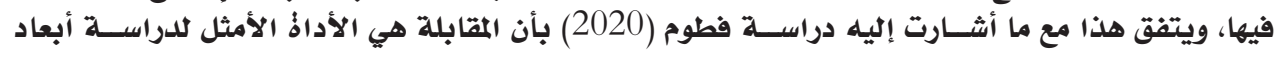
الحوكمة؛ إذ يمكن من خلالها الاطلاع ما ألياه على الحقائق عن كثب.

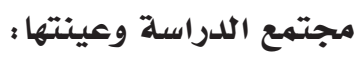

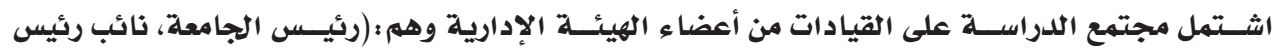

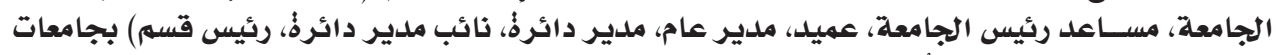

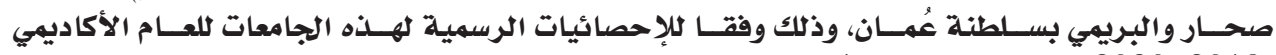

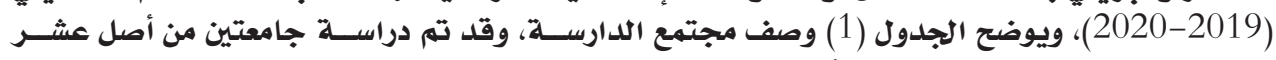

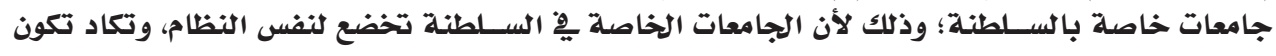

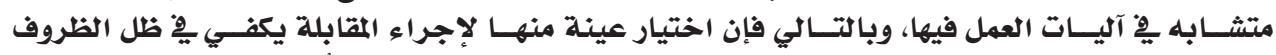

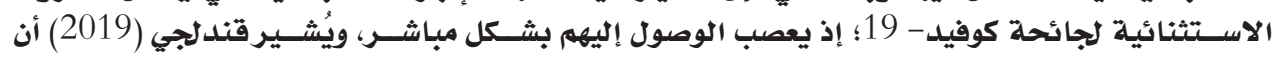

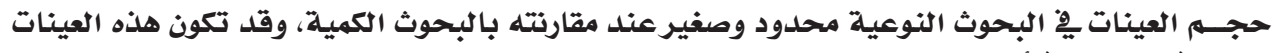

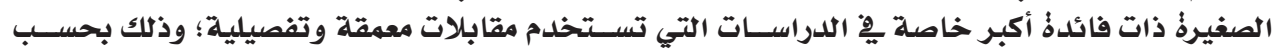

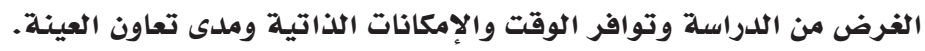


خليفة بن محمد الفتحي داوود عبدالملك الحدابي وجيهة ثابت العاني ميراح سعود

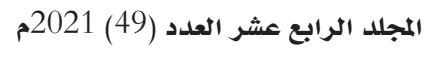

جدول (1): مجتمع الدراسة

\begin{tabular}{|c|c|c|}
\hline \multicolumn{2}{|c|}{ القيادات من أعضاء الهيئة الإدارية } & الجامعات \\
\hline$\% 65$ & 40 & جامعة صحار \\
\hline$\% 35$ & 22 & جامعة البريمي \\
\hline$\% 100$ & 62 & المجموع \\
\hline
\end{tabular}

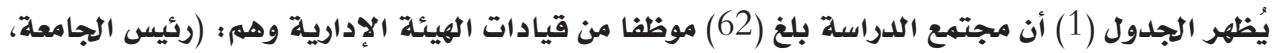

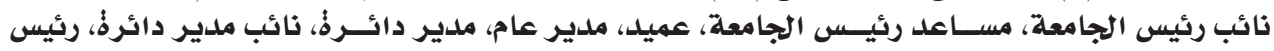

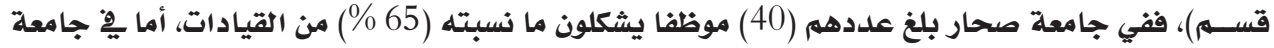

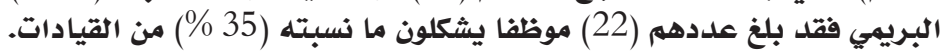

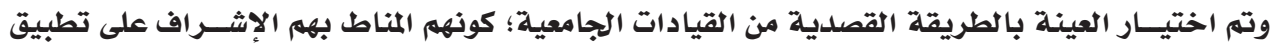

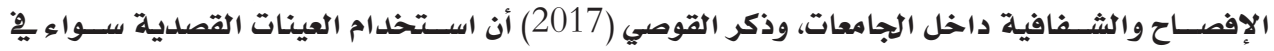

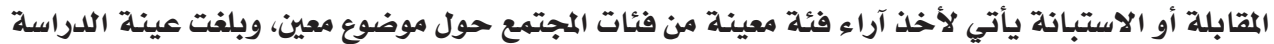

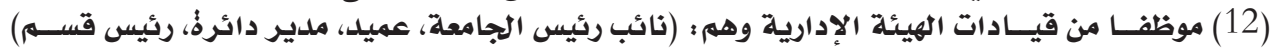

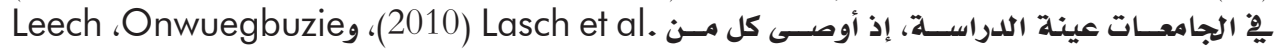

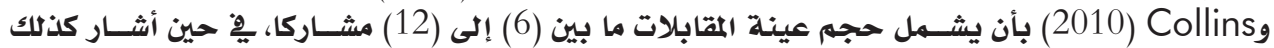

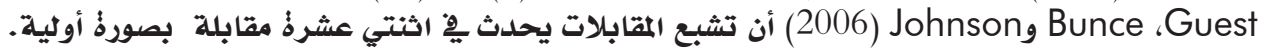
أداذٌ الدراسلة :

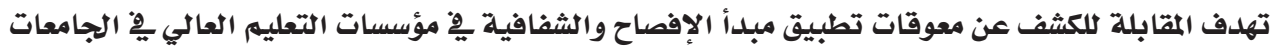

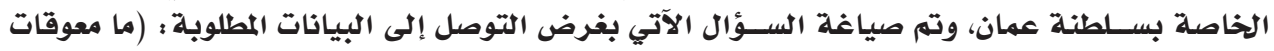

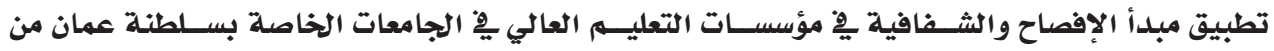

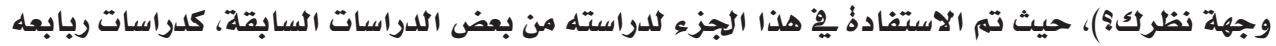
والشرمان (2017).

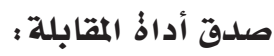

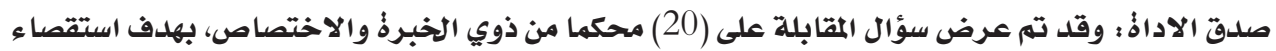

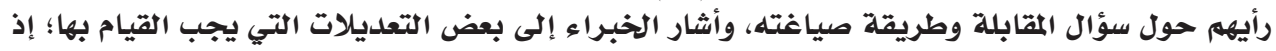

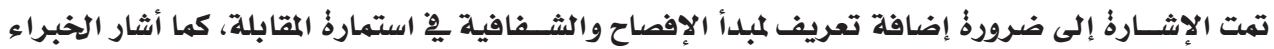

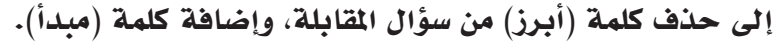

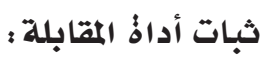

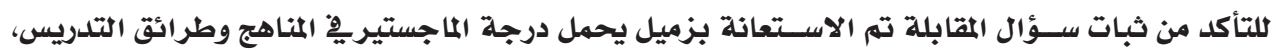

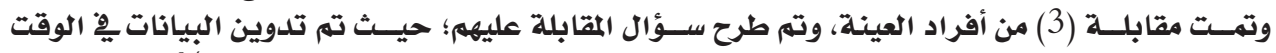

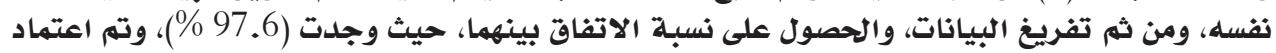

سؤال المقابلة بصيغته النهائية.

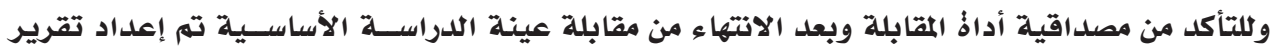

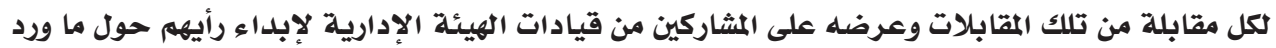

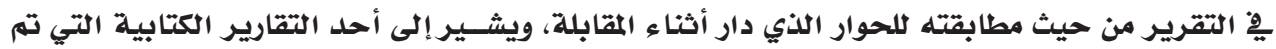

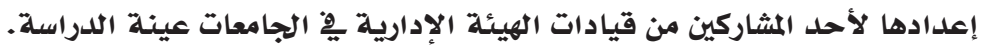




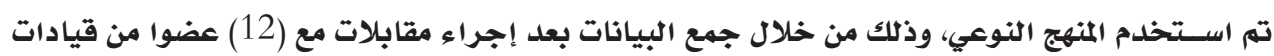

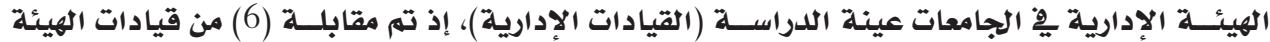

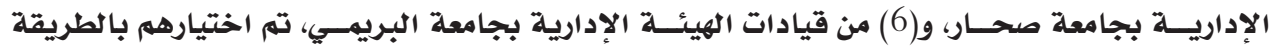

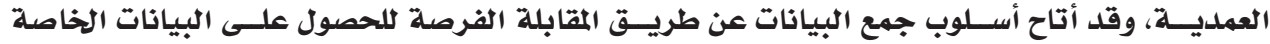

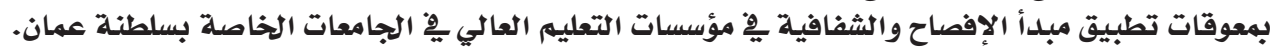

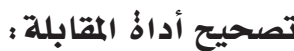

كلاستفادذٌ من البيانات التي تم جمعها والحصول عليها عن طريق المقابلة تم تحليلها ثم كتابتها وتصنيفها

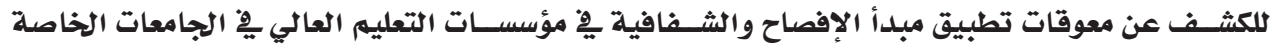

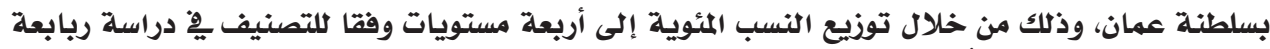

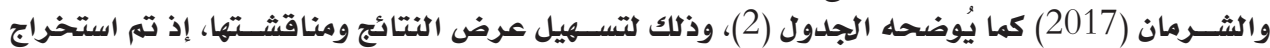

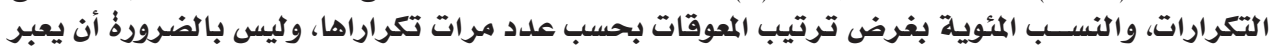

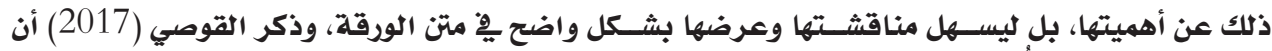

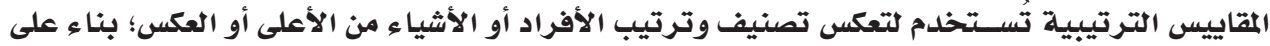

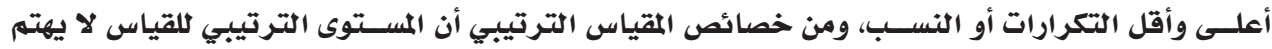
بالفروق بين العناصر أو الأشياء المرتبة أنسية جدول (2) : توزيع النسب المئوية

\begin{tabular}{|c|c|}
\hline المستوى ل الم & النسبة المئوية \\
\hline منخفض & (25 \%) فأقل \\
\hline متوسط & من (26 \%) !ٕلى (50 \%) \\
\hline مرتفع & من (51 \%) إلى (75 \%) \\
\hline مرتفع جدا & من (76 \%) فأكثر \\
\hline
\end{tabular}

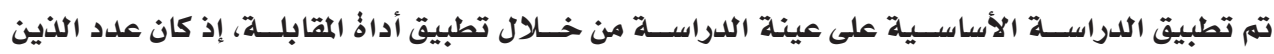

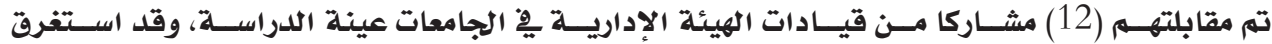

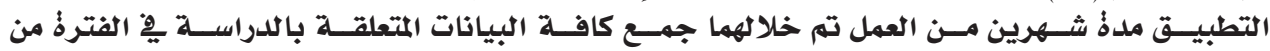
2020/9/23)

وقد تم اتباع الخطوات الآتية لتحقيق أغراض الدراسة :

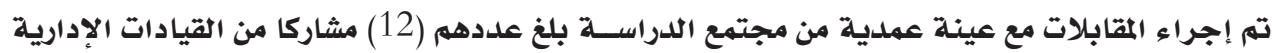
مِّ الجامعات عينة الدراسة.

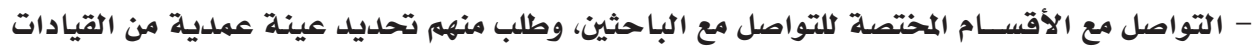
الإدارية يِّ تلك الجامعات، وتحديل موعد مسبق للجلوس معهم ومقابلتهم.

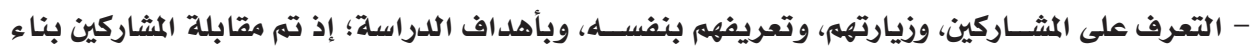

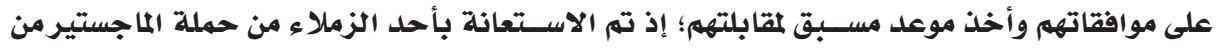

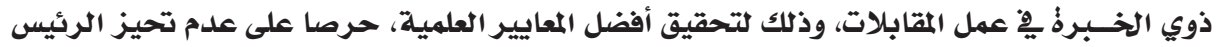
نحو نتائج معينـة أثناء المقابلة.

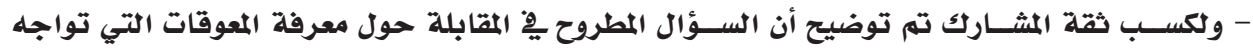

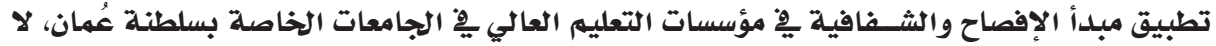

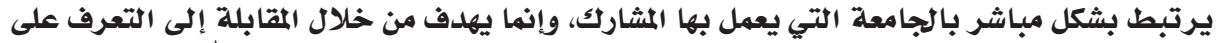

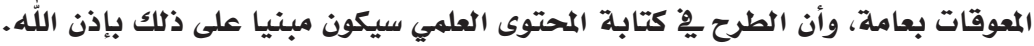


خليفة بن محمد الفتحي داوود عبدالملك الحدابي وجيهة ثابت العاني ميراح سعود

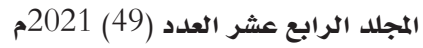

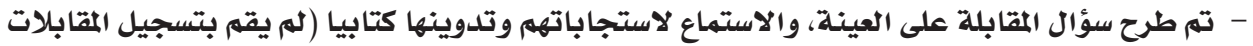

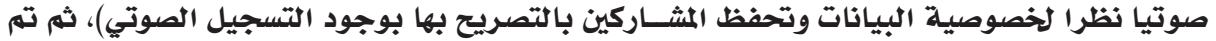

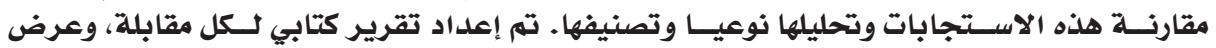

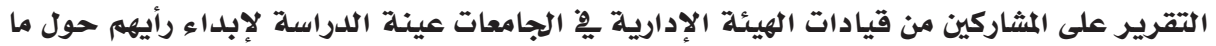

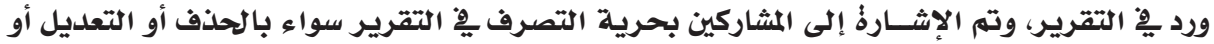

الإضافة.

\section{المعالجات الإحصائية:}

للإجابلة عن سؤال الدراسة تم رصد وتحليل محتوى استجابات أفراد العينة على المقابلة، وتوزيعها للفئات

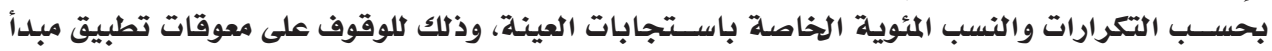

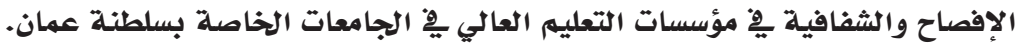

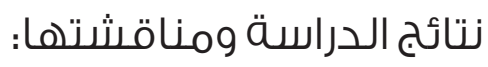

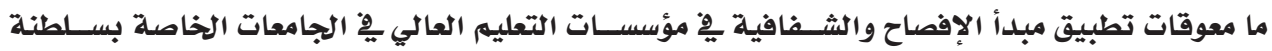

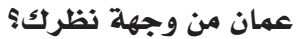
وللوصول إلى الإجابة عن هذا السؤال :

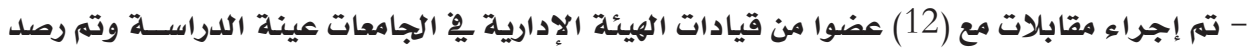

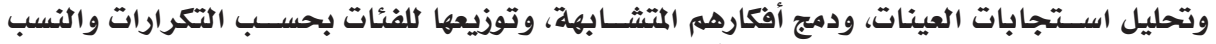

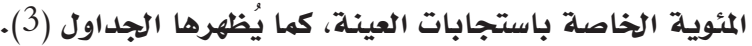

جلدول (3): التكرارات والنسب المئوية لاستجابات أفراد عينة الدراسة حول معوقات تطبيق مبدأ الإفصاح والشفافية يْ مؤسسات

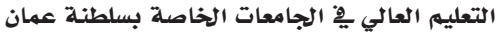

\begin{tabular}{|c|c|c|c|c|}
\hline 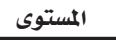 & النسبة المئوية & 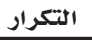 & معوقات تطبيق الإفصاح والشفافية & م \\
\hline 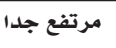 & $\% 83$ & 10 & ضعف شفافية الإفصاح عن ميزانية الجامعة وبنود الصرف & 1 \\
\hline متوسط متط & $\% 50$ & 6 & ضعف المصداقية والشفافية عند تطبيق السياسات وضوابط العمل الداخلية & 2 \\
\hline 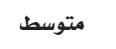 & $\% 50$ & 6 & خضوع تقييم أداء الموظف للتقدير الشخصي من المسؤول المباشر & 3 \\
\hline متوسط & $\% 50$ & 6 & ضعف ثقافة المدراء والموظفين بأهمية الإفصاح والشفافية & 4 \\
\hline 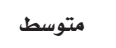 & $\% 50$ & 6 & إدراج الجامعات تحت مظلة أحد شركات المساهمة العامة & 5 \\
\hline 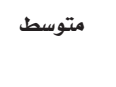 & $\% 50$ & 6 & عدم توازن سلالم الرواتب الوظيفية على مستوى الجامعة الواحدةً أو على الجماتى & 6 \\
\hline متوسط & $\% 50$ & 6 & عدم وجود نظام الكتروني متكامل ِِِ الجامعة & 7 \\
\hline 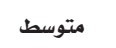 & $\% 50$ & 6 & تدخل أصحاب القرار ِِّ عمليات التوظيف & 8 \\
\hline 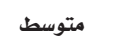 & $\% 42$ & 5 & قلة وضوح معايير التوظيف والحوافز & 9 \\
\hline 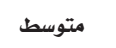 & $\% 42$ & 5 & وجود سياسة التكتم أو السرية يِّ تسيير الأعمال & 10 \\
\hline 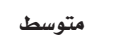 & $\% 42$ & 5 & ضعف اطلاع الموظفين على البيانات والمعلومات & 11 \\
\hline 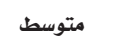 & $\% 42$ & 5 & تفشي سياسة المجاملة عند تطبيق معايير التقييم والحوافز بين العاملين & 12 \\
\hline 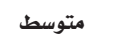 & $\% 42$ & 5 & عدم وجود قاعدةٌ بيانات موحدة لموظفي الجامعات الخاصة ِِِ سلطنة عُمان & 13 \\
\hline 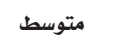 & $\% 42$ & 5 & قلة وضوح معايير التقييم السنوي للموظف & 14 \\
\hline 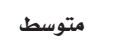 & $\% 33$ & 4 & عدم التزام الجامعات بهامش محدد من الربحية السنوية & 15 \\
\hline متوسط & $\% 33$ & 4 & قلة الإفصاح والشفافية ِِِ آليات التوظيف & 16 \\
\hline 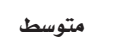 & $\% 33$ & 4 & ضعف آليات البحث والتقصي حول مؤهلات الموظف الجديد & 17 \\
\hline 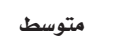 & $\% 33$ & 4 & لجان التدقيق والمراقبة لا تستخدم سياسة الزيارة المفاجئة & 18 \\
\hline 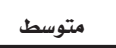 & $\% 33$ & 4 & الاهتمام بضم أعداد أكبر من الطلاب على حساب الكيف & 19 \\
\hline
\end{tabular}


جلدول (3)) : بتبع

\begin{tabular}{|c|c|c|c|c|}
\hline 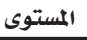 & النسبة المئوية & 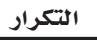 & معوقات تطبيق الإفصاح والشفافية & م \\
\hline 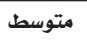 & $\% 33$ & 4 & التأخر بِّ الإفصاح (والإفصاح بِ الوقت غير المناسب) & 20 \\
\hline 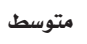 & $\% 33$ & 4 & اللغة (ِِّ حال وجود إدارات وكليات تستخدم لغة غير تلك اللغة المعتمدة؛) & 21 \\
\hline 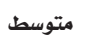 & $\% 33$ & 4 & عدم وجود لجنة أو جهة محددةُ داخل الجامعة للتدخل ِِّ حل المشكلات & 22 \\
\hline 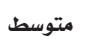 & $\% 33$ & 4 & ضعف وضوح سياسة التظلمات ِِّ الجامعات & 23 \\
\hline 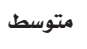 & $\% 33$ & 4 & قلة إيمان الإدارةٌ العليا بأهمية الشفافية ِِّ العمل الإداري & 24 \\
\hline 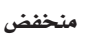 & $\% 25$ & 3 & التداخل ِِْ الأدوار بين الأقسام & 25 \\
\hline 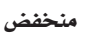 & $\% 25$ & 3 & ضعف وضوح النشر بين الصلاحيات والمسؤوليات الإدارية & 26 \\
\hline منخفض & $\% 25$ & 3 & عدم وجود نظام واضح للترقيات & 27 \\
\hline
\end{tabular}

من خلال المقابلات التي تم القيام بها والحلديث المطول مع أفراد العينـة فإنه تم استعراض نتائج هذا المحور ويمكن تفسيرها على النحو الآتي :

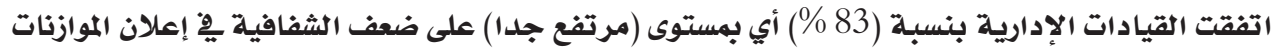

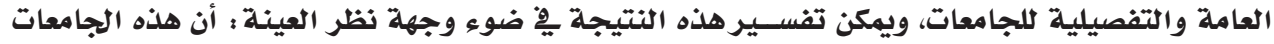

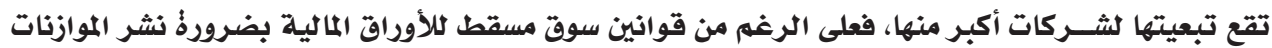

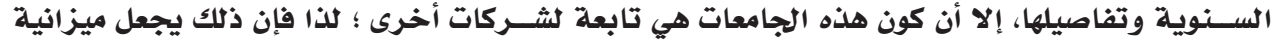

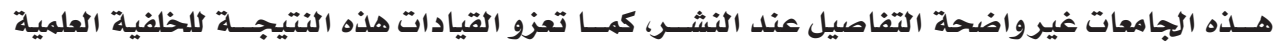

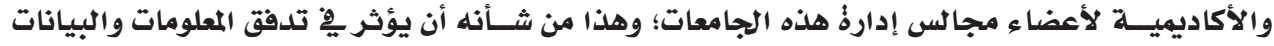

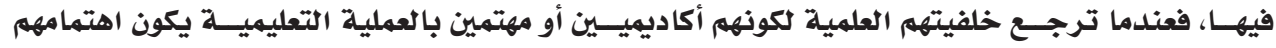

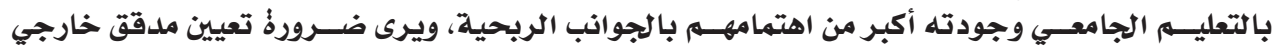

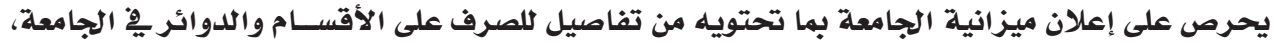

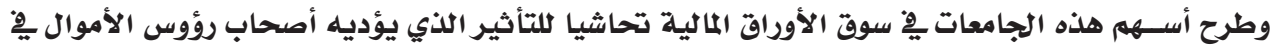
إدارةٌ تلك الجامعات.

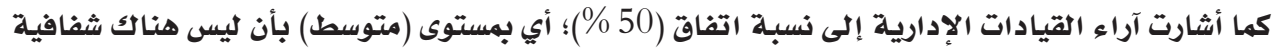

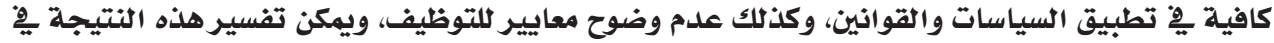

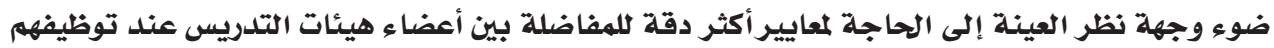

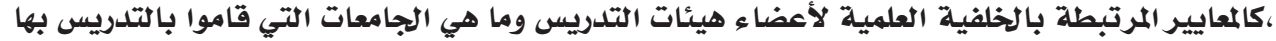

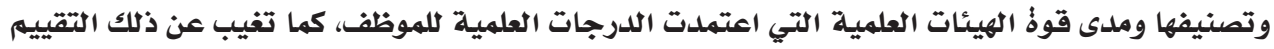

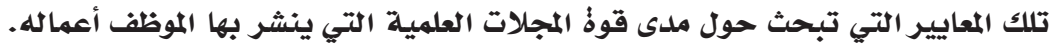

وبيَنت نتائج التحليل اتفاق القيادات الإدارية بنسـبـة (50 \%) أي بمســتوى (متوسط) على أن تقييم أداء

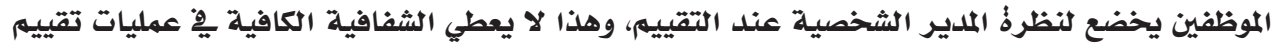

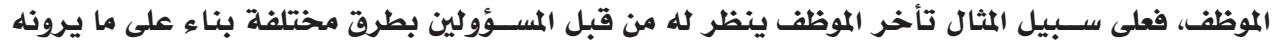

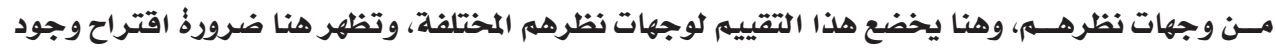

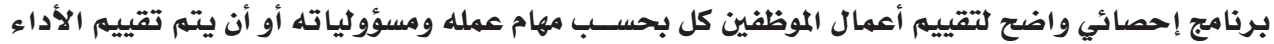

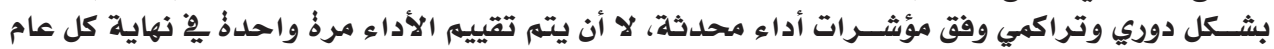
أكادييمي.

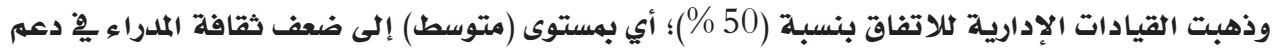

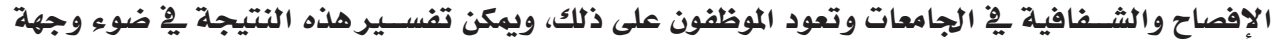

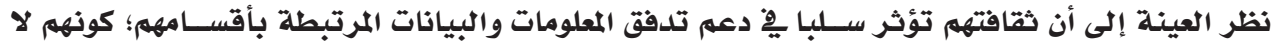

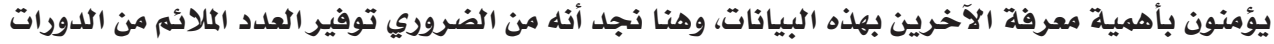


خليفة بن محمد الفتحي داوود عبدالملك الحدابي وجيهة ثابت العاني ميراح سعود

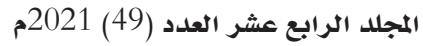

-

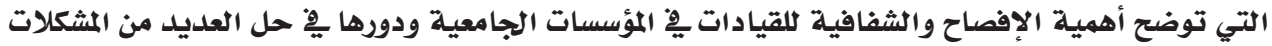

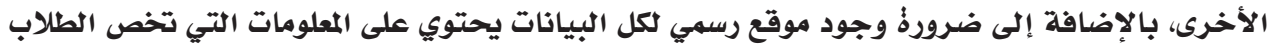
والموظفين وحتى أولياء الأمور.

كما أثــارت القيادات الإداريـة كذلك للاتفاق بنسـبـة (42 \% \%)؛ أي بمســتوى (متوسط) لقلة وضوح معايير

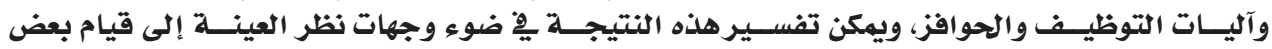

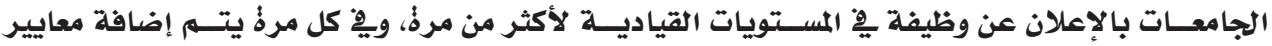

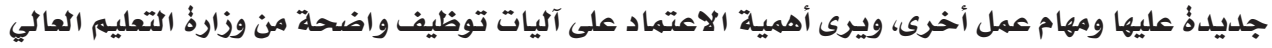

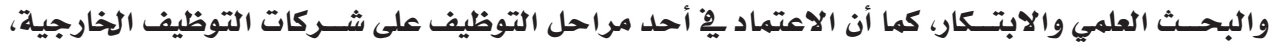

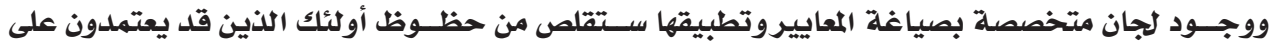

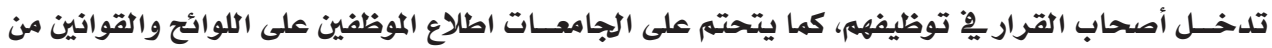

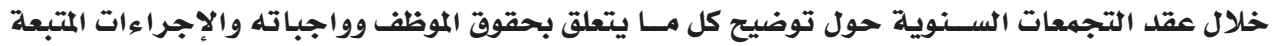

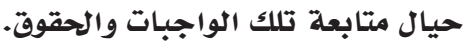

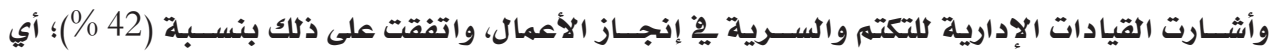

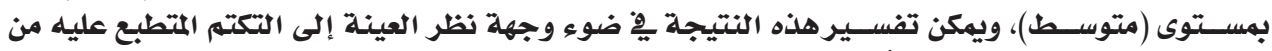

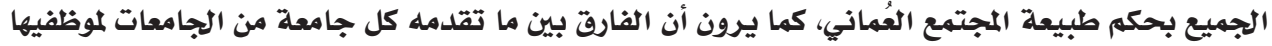

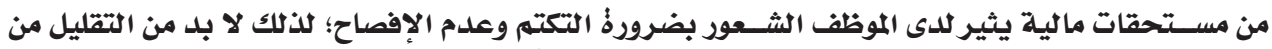

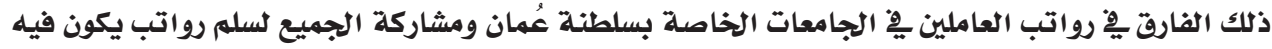

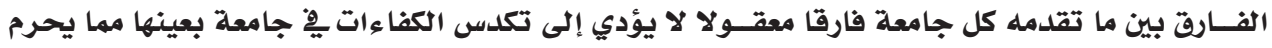

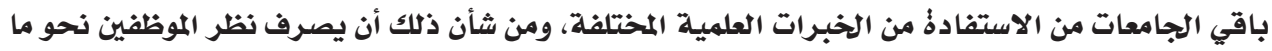

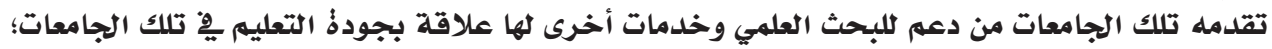

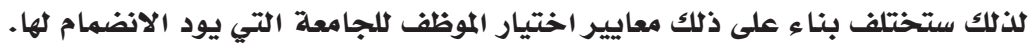

كما اتفقت آراء القيادات الإدارية بنسبة (42 \%)؛ أبي بمستوى (متوسط) على أن هناك الكثير إنير من المجاملات

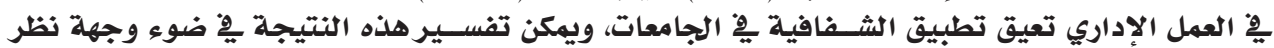

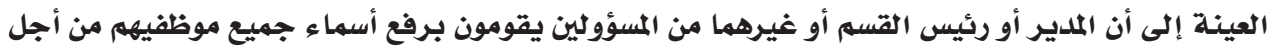

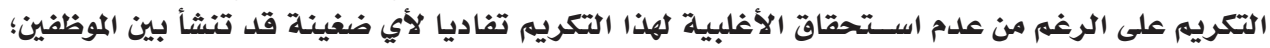

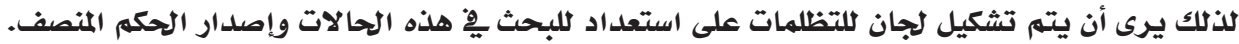

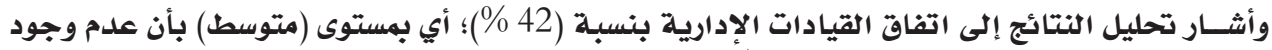

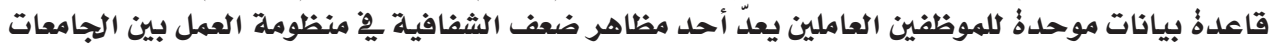

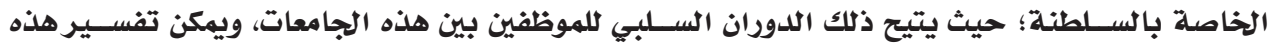

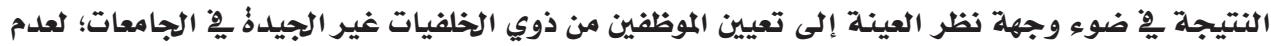

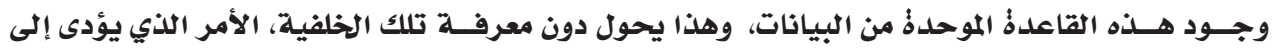

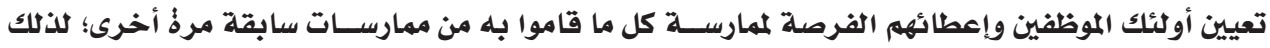

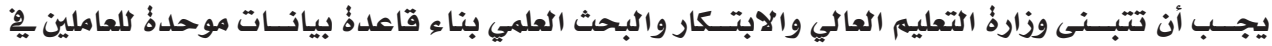
الجامعات الخاصة بالسلطنة تصنة

واتفقت القيادات الإدارية بنسبة (33 \%)؛ أي بهستوى (متوسط) على عدم التزام الجامعات بنسبة معينة

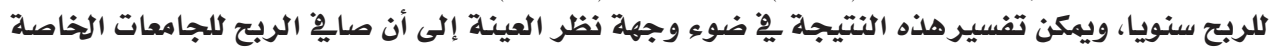

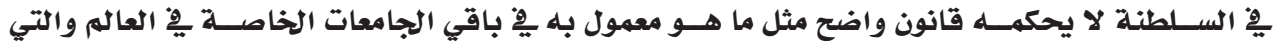

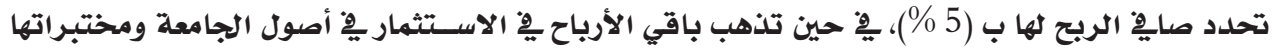

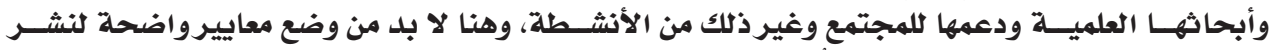

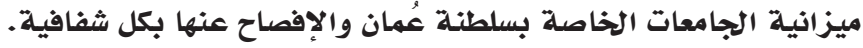




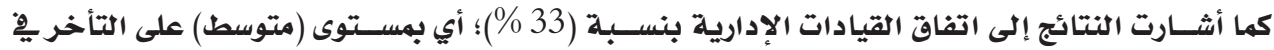

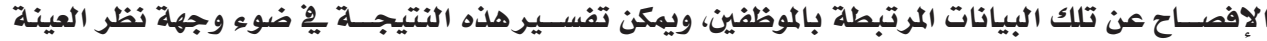

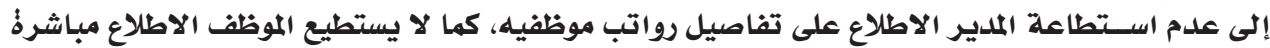

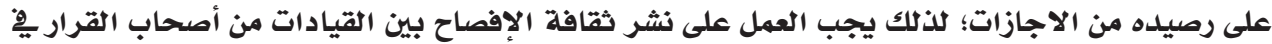

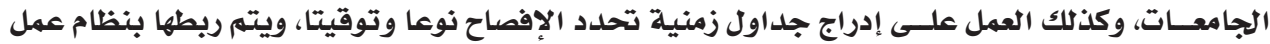

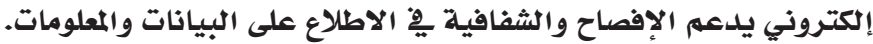

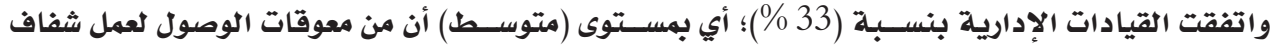

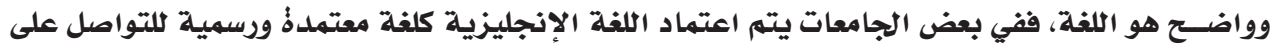

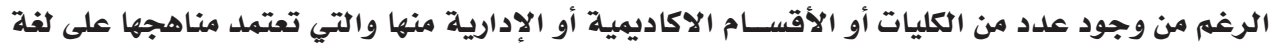

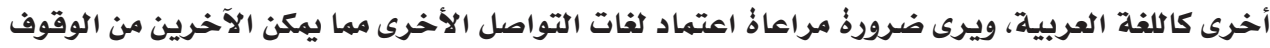
على كل النقاط بوضوح وشفافية.

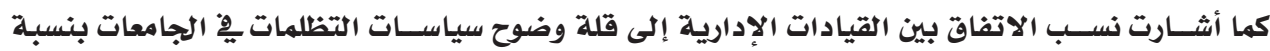

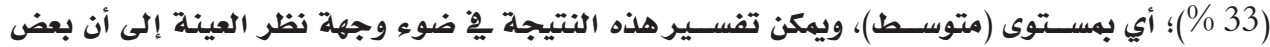

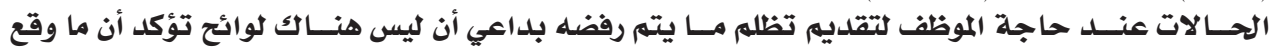

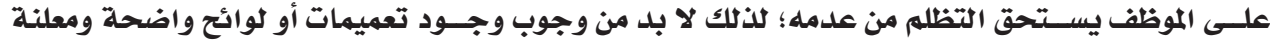

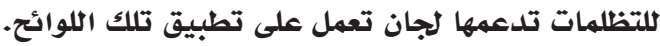

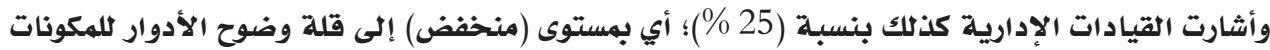

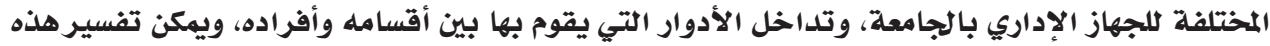

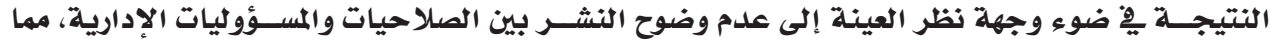

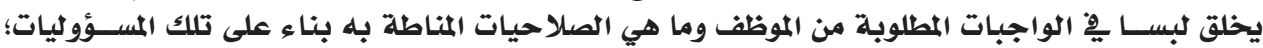

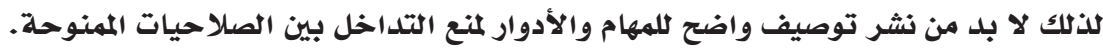

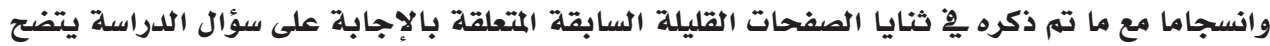

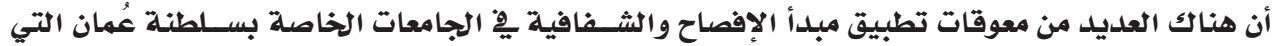

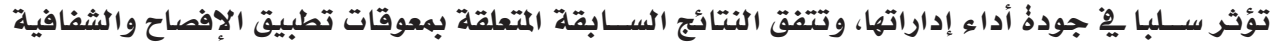

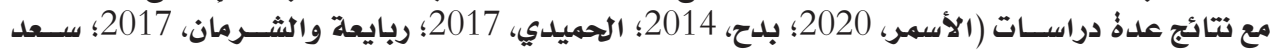

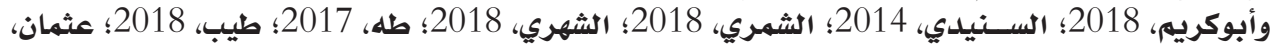
2017؛ الهندي وآخرون، 2019) التي أشارت إلى وجود العديل من معوقات تطبيق مبدأ الإفصاح والشفافية

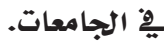

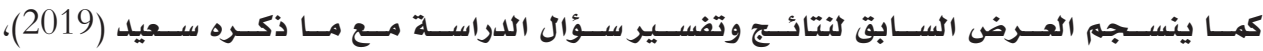

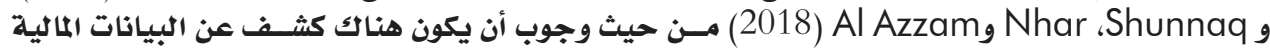

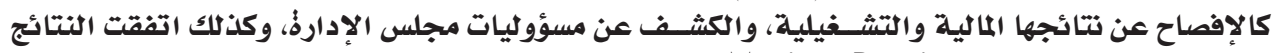

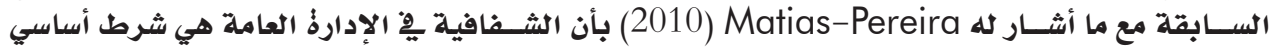

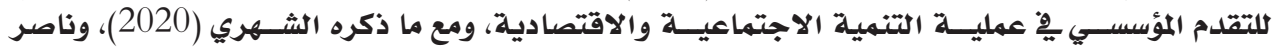

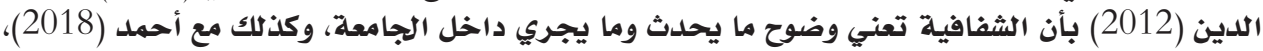

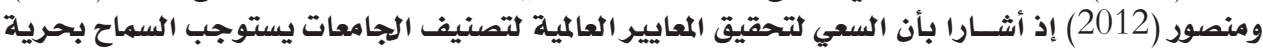

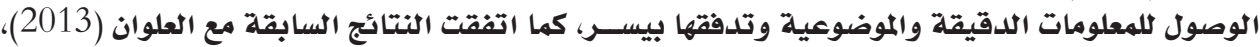

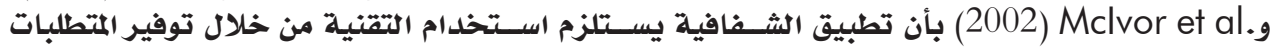

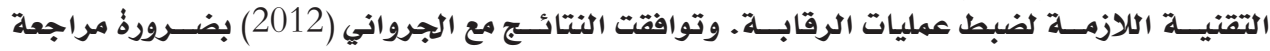

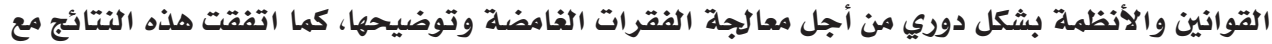

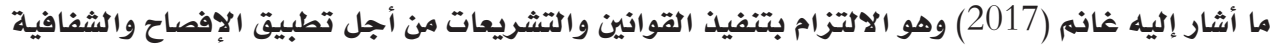


خليفة بن محمد الفتحي داوود عبدالملك الحدابي وجيهة ثابت العاني ميراح سعود

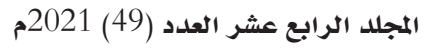

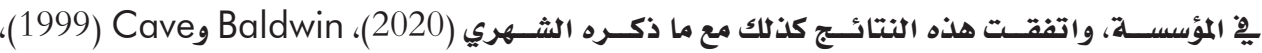
و. Harpe et al

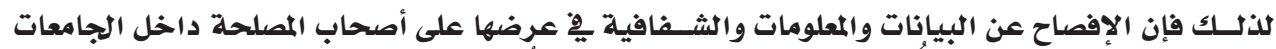

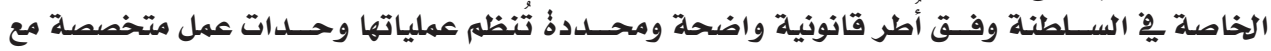

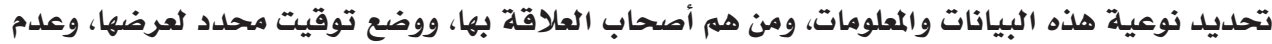

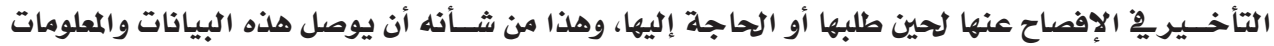

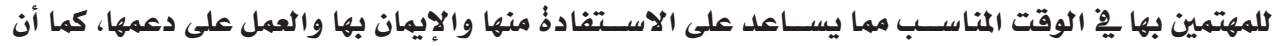

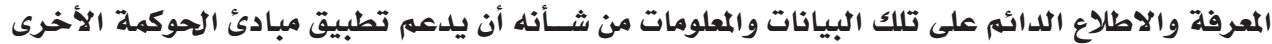

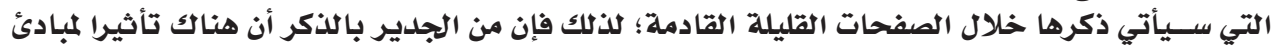

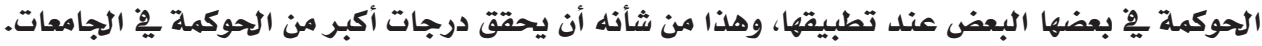

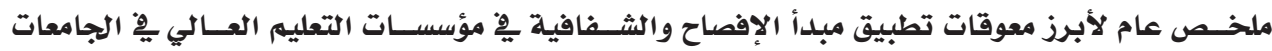

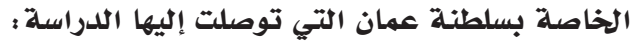

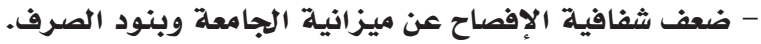

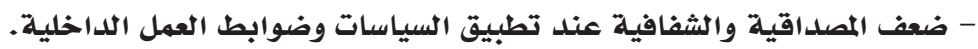

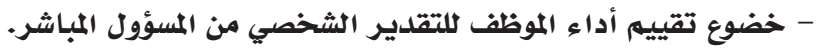

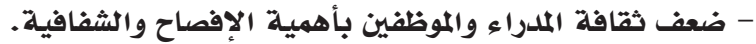

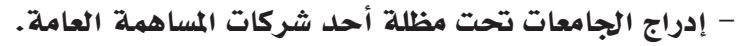

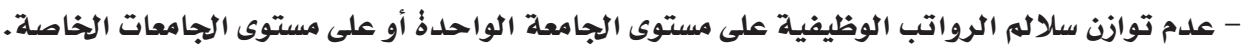

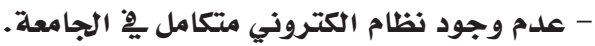
- تلدخل أصحاب القرار يِّ عمليات التوظيف.

الالستنتاجات:

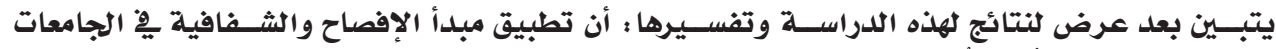

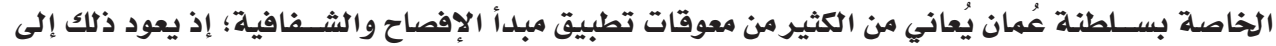

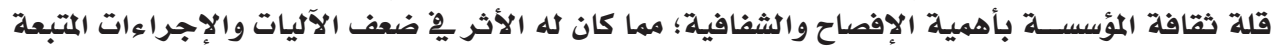

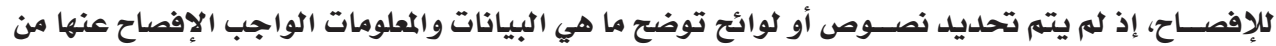

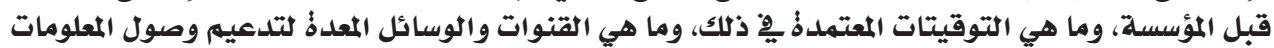

والبيانات لمستحقيها.

التوصيات:

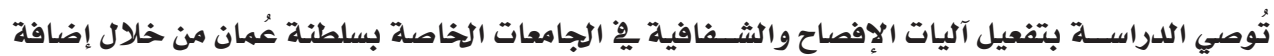

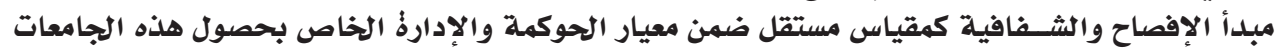

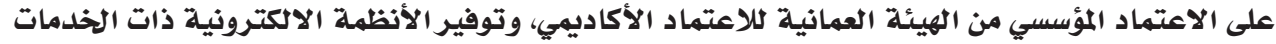

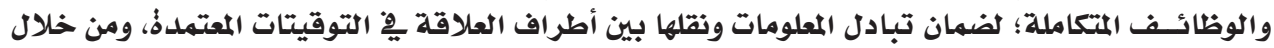

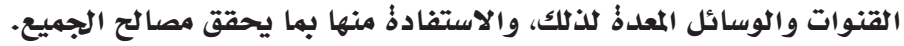

المقترحات:

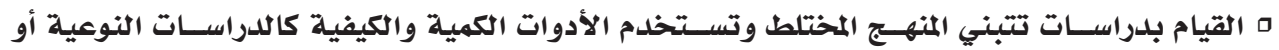

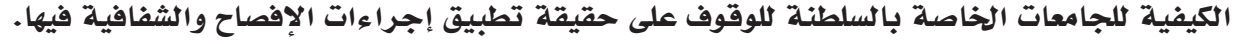
ه دراسة معمقة لوضع إجراءات تطبيق الإفصاح والثفافية ِِِ الجامعات الخاصة بسلطنة عُمان. 
أحمد، سماح محمد سيد (2018). التصنيفات العالمية للجاهعات. القاهرةٌ : العربي للنشر والتوزيع.

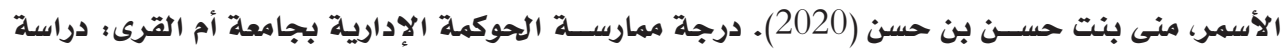

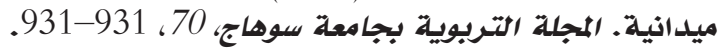

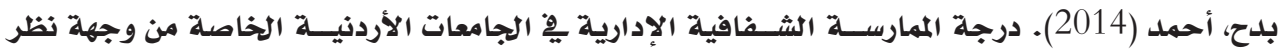

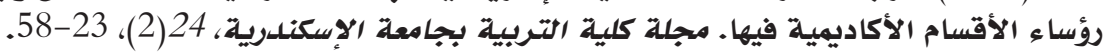

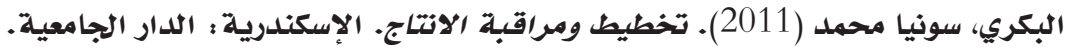

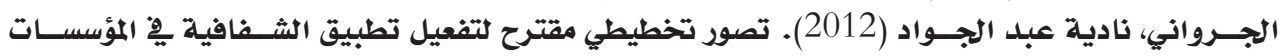

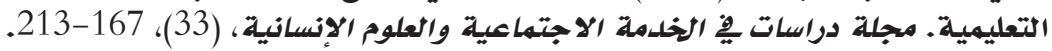

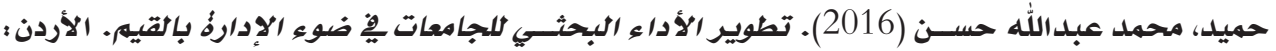
دار غيداء للنشر والتوزيع. ميد.

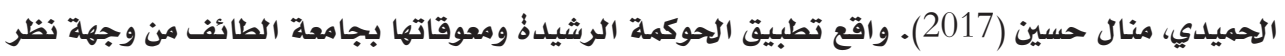

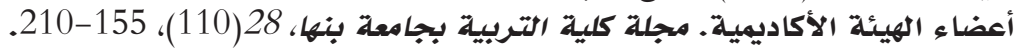

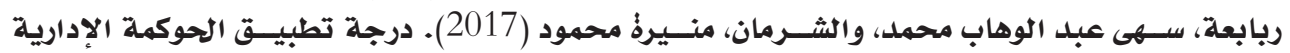

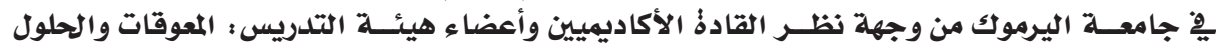

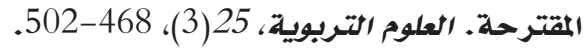

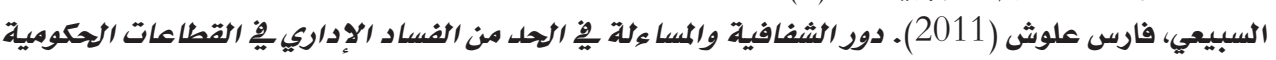

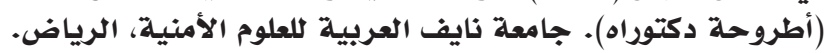

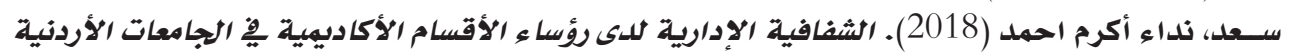

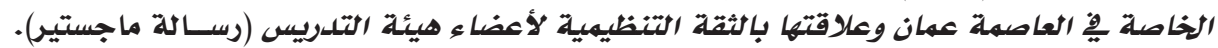
جامعة الشرق الأوسط، الأردن. سعيد، شوقي طارق (2019). محاسبة الشركات. الأردن : دار غيداء اللنشر الأرو والتوزيع.

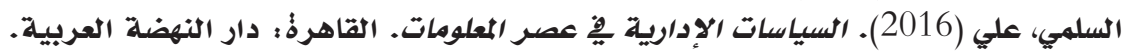

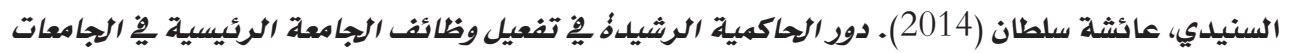

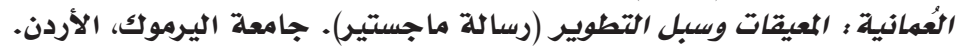

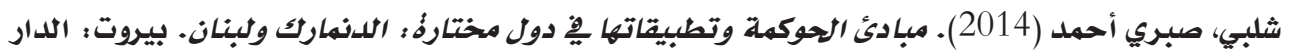
العربية للموسوعات.

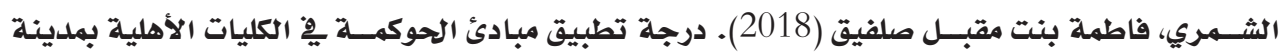

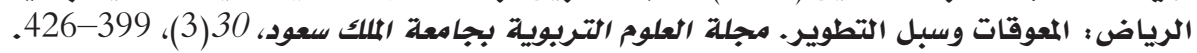

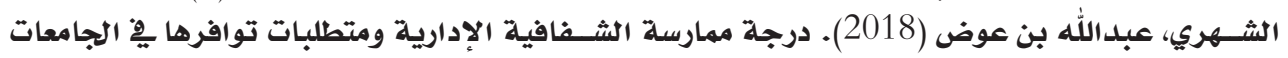

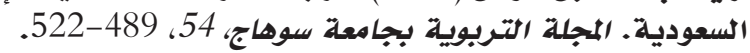

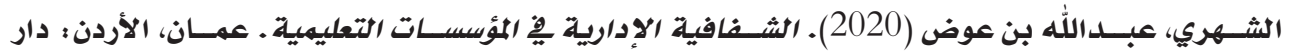
اليازوري للنشر والتوزيع.

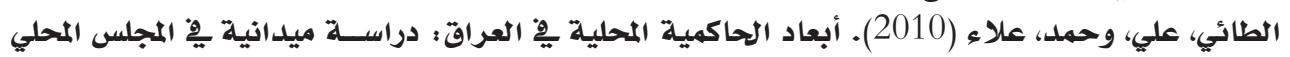

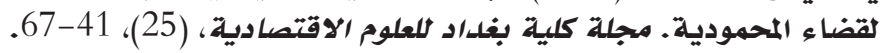

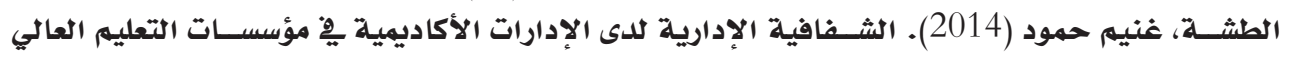

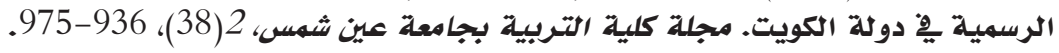

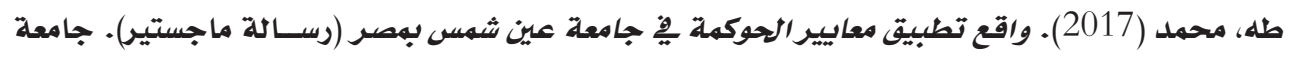
عين شمس، مصر. 
خليفة بن محمد الفتحي داوود عبدالملك الحدابي وجيهة ثابت العاني ميراح سعود المجلد الرابع عشر العدد (49) 2021مابت العاني ميرح

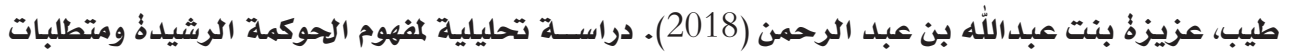

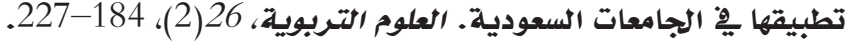

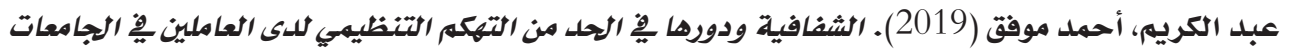
الأردنية الخاصة (رسالة ماجستير). جامعة آل آل البيت، الأردن.

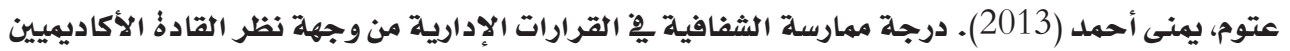

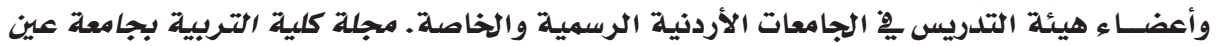

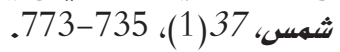

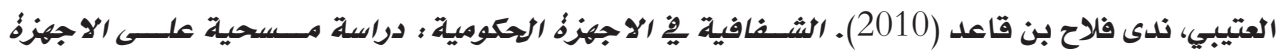

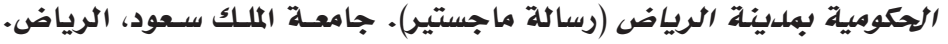

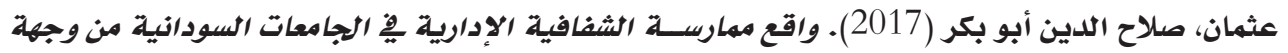

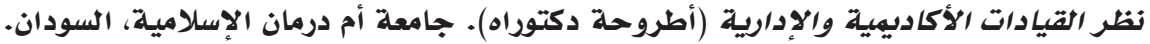

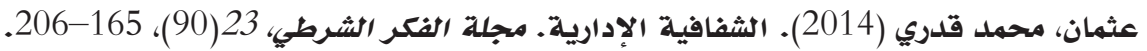

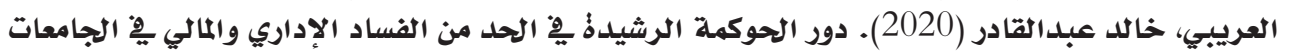

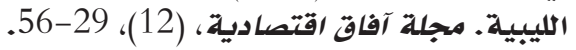

العضايلة، محمد (2000). الشـفافية ومكافحة الفساد. الأردن ؛ مؤسسة الأرشيف الوطني نحو الشفافية الأردنية.

العلوان، جعفر أحمد (2013). الشفافية الإدارية بين المفهوم والتطبيق. مجلة التنهية الإدارية، (102).

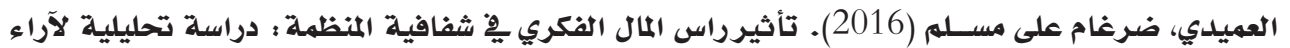

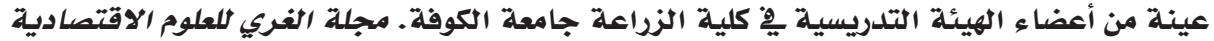

$$
\text { والإداريية، (37)، 216-232-232. }
$$

عويس، محمد زكي (2012). ثورة مصر ومستقبل التعليه العالي. مصارية مصر : المكتبة الاكاديمية.

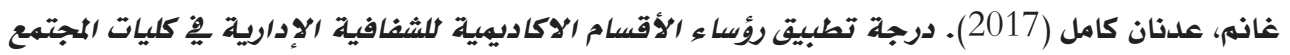

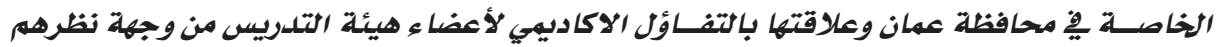

(رسالة ماجستير). جامعة الشرق الأوسط، الأردان.

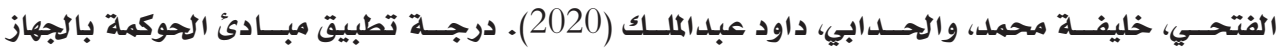

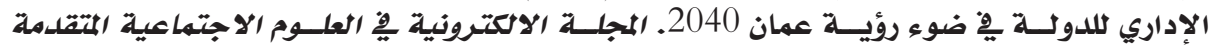

$$
\text { .633-616، (15ASOS) }
$$

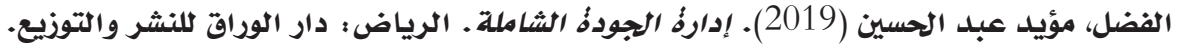

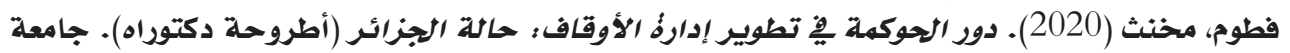
زيان عاشور، الجلفة، الجزائر.

قندلجي، عامر (2019). منهجية البحث العلهي. الأردن ؛ دار اليازوري العلمية العية للنشر والتوزيع.

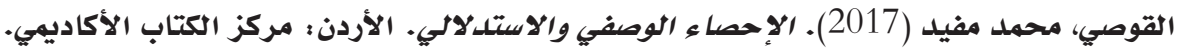

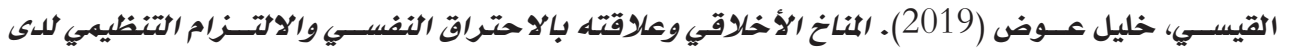

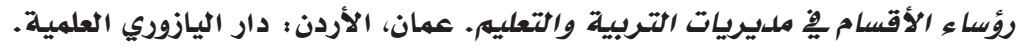

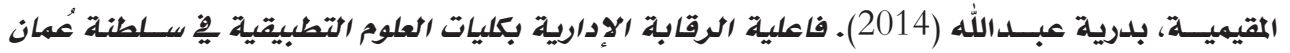

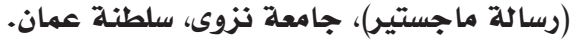

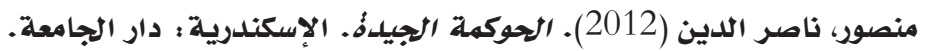

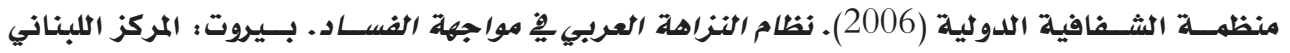
للدراسات. 


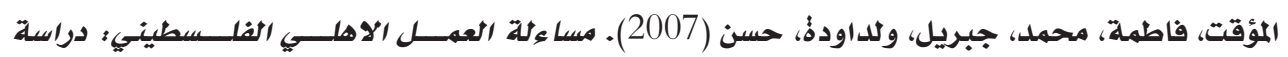

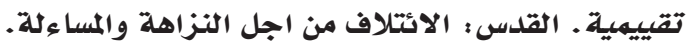

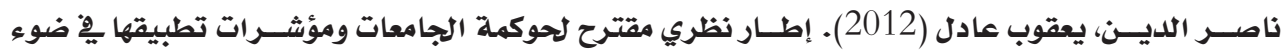

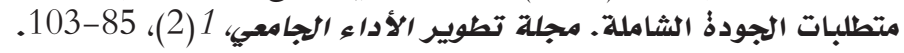

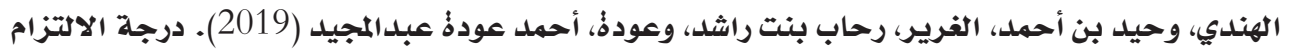

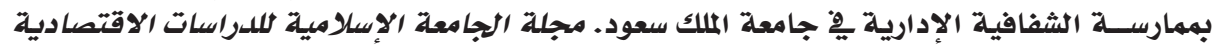

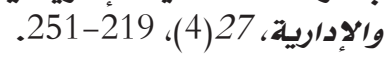

الهيئة العُمانية كلاعتماد الاكاديمي (2021). نتائج المرحلة الثانية من الثانية عملية الاعتهاد المؤسسي. استرجع

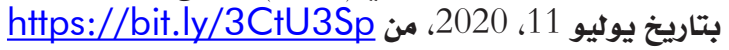

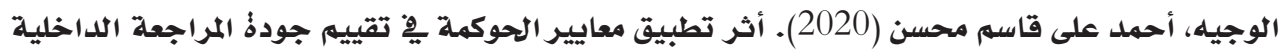

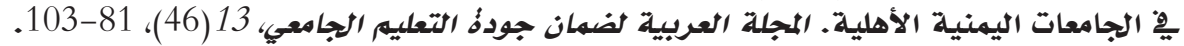

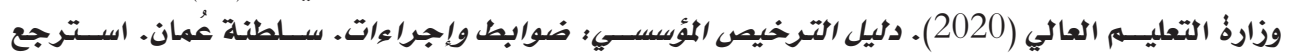

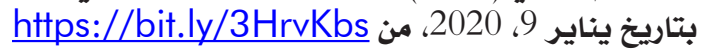

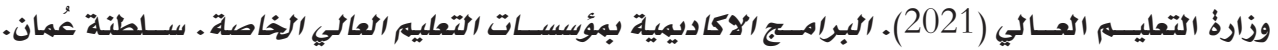

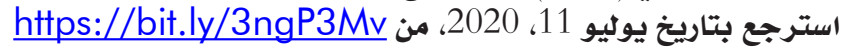

Baldwin, R., \& Cave, M. (1999). Understanding regulation: Theory, strategy and practice. Oxford: Oxford University Press.

Guest, G., Bunce, A., \& Johnson, L. (2006). How many interviews are enough? An experiment with data saturation and variability. Field Methods, 18(1), 59-82.

Harpe, S., Rijken, C., \& Roos, R. (2008). Good governance. Potchefstroomse Elektroniese Regsblad, 17(2), 2-15.

Hénard, F., \& Mitterle, A. (2010). Governance and quality guidelines in Higher Education: A review of governance arrangements and quality assurance. Berlin: OECD.

Johnston, M. (2006). Good governance: Rule of law, transparency, and accountability. New York: United Nations Public Administration Network.

Lasch, K. E., Marquis, P., Vigneux, M., Abetz, L., Arnould, B., \& Bayliss, M. (2010). PRO development: Rigorous qualitative research as the crucial foundation. Quality of Life Research, 19(8), 1087-1096.

Matias-Pereira, J. (2010). Public administration course: focus on government institutions and actions ( $3^{\text {rd }}$ ed.). São Paulo: Atlas.

Mclvor, R., McHugh, M., \& Cadden, C. (2002). Internet technologies: supporting transparency in the public sector. International Journal of Public Sector Management, 15(3), 170-187.

National Academies of Sciences, Engineering, \& Medicine (2017). Human genome editing: Science, ethics, and governance. National Academies Press. 
خليفة بن محمد الفتحي داوود عبدالملك الحدابي وجيهة ثابت العاني ميراح سعود

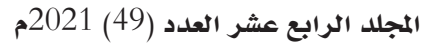

Onwuegbuzie, A. J., Leech, N. L., \& Collins, K. M. T. (2010). Innovative data collection strategies in qualitative research. The Qualitative Report, 15(3), 696-726.

Schnackenberg, A. K., \& Tomlinson, E. C. (2016). Organizational transparency: A new perspective on managing trust in organization-stakeholder relationships. Journal of Management, 42(7), 1784-1810.

Shunnaq, A., Nhar, M. F., \& Al Azzam, F. A. F. (2018). Jordanian corporate governance, and their impact on transparency and objective disclosure: A comparative study. Journal of Law, Policy and Globalization, 75, 46-54.

Zaman, K. (2015). Quality guidelines for good governance in higher education across the globe. Pacific Science Review B: Humanities and Social Sciences, $7(1), 1-7$.

\section{Arabic References in Roman Scripts:}

Abdulkarim, Ahmed Mowaffaq (2019). Alshafaafiat wadawruha fi alhadi min altahakum altanzimii ladaa aleamilin fi aljamieat al'urduniyat alkhasa (Risalat majistir). Jamieat Aal Albit, Al'urdunn.

Ahmed, Samah Mohamed Sayed (2018). Altasnifat alealamiat liljamieati. Alqahiratu: Alearabii Lilnashr Waltawziei.

Al-Adayleh, Muhammad (2000). Alshafaafiat wamukafahat alfasadi. Al'urduni: Muasasat Al'arshif Alwatanii Nahw Alshafaafiat Al'urduniyati.

Al-Araibi, Khaled Abdel-Qader (2020). Dawr alhawkamat alrashidat fi alhadi min alfasad al'iidarii walmalii fi aljamieat Alliybiati. Majalat Afaq Aiqtisadiat, (12), 29-56.

Al-Asmar, Mona bint Hassan bin Hassan (2020). Darajat mumarasat alhawkamat al'iidariat bi Jamieat Umm Alquraa: Dirasat maydaniatun. Almajalat Altarbawiat bi Jamieat Suhai, 70, 931-982.

Al-Bakri, Sonia Mohamed (201 1). Takhtit wamuraqabat aliantaji. Al'iiskandiriati: Aldaar Aljamieiatu.

Aleamidi, dargham ealaa muslim (2016). Tathir ras almal alfikrii fi shafaafiat almunazamati: Dirasat tahliliat lara' eayinat min 'aeda' alhayyat altadrisiat fi kuliyat alziraeat jamieat alkufa. Majalat Algharii Lileulum Alaiqtisadiat Wal'iidariati, (37), 216-232.

Al-Fadl, Muayyad Abdul-Hussein (2019). Idarat aljawdat alshaamilati. Alrayad: Dar Alwaraq Lilnashr Waltawziei.

Al-Fatihi, Khalifa Muhammad, wa Al-Hadabi, Daoud Abdul-Malik (2020). Darajat tatbiq mabadi alhawkamat bialjihaz al'iidarii lildawlat fi daw' ruyat eamaan 2040. Almajalat Alalkitruniat fi Aleulum Aliaijtimaeiat Almutaqadima (IJASOS), 6(16)616-633. 
Alhayyat Aleumanyt Liliaetimad Alakadimii (2021). Natayij almarhalat althaaniat min eamaliat aliaetimad almuasisii. Asturjie bitarikh Yuliu 11, 2020, min https://bit.ly/3C+U3Sp

Al-Hindi, Waheed bin Ahmed, Al-Ghurair, Rehab bint Rashid, wa Odeh, Ahmed Odeh Abdulmajeed (2019). Darajat alailtizam bimumarasat alshafaafiat al'iidariat fi Jamieat Almalik Saeud. Majalat Aljamieat Al'iislamiat Lildirasat Alaiqtisadiat Wal'iidariati, 27(4), 219-251.

Al-Humidi, Manal Hussein (2017). Waqie tatbiq alhawkamat alrashidat wamueawiqatiha bi Jamieat Altaayif min wijhat nazar 'aeda' alhayyat al'akadimiati. Majalat Kuliyat Altarbiat bi Jamieat Binha, 28(110), 155-2 10.

Al-Jarwani, Nadia Abdel-Gawad (2012). Tasawur takhtitiun muqtarah litafeil tatbiq alshafaafiat fi almuasasat altaelimiati. Majalat Dirasat fi Alkhidmat Alaijtimaeiat Waleulum Al'iinsaniati, (33), 167-213.

Al-Muaqat, Fatima, Muhammad, Gabriel, and Waldaouda, Hassan (2007). Musa'alat aleumli alahlayi alfalistinii: Dirasat taqyimiata. Alquds: Alaitilaf min Ajil Alnazahat Walmusa'alati.

Al-Muqimia, Badria Abdullah (2014). Faeiliat alraqabat al'iidariat bikuliyaat aleulum altatbiqiat fi Saltanat Oman (Risalat majistir). Jamieat Nazwaa, Saltanat Oman.

Al-Otaibi, Nada Falah bin Qaed (2010). Alshafaafiat fi alajihizat alhukumiati: Dirasat musahiat eala alajihizat alhukumiat bi Madinat Alriyad (Risalat majistir). Jamieit Almulk Saeud, Alriyad.

Al-Qaisi, Khalil Awad (2019). Almunakh al'akhlaqiu waealaqatuh bialaihtiraq alnafsii walailtizam altanzimii ladaa ruasa' al'aqsam fi mudiriaat altarbiat waltaelimi. Amman, Al'urdunn: Dar Alyazurii Aleilmiati.

Al-Qussi, Muhammed Mufid (2017). Al'iihsa' alwasfiu waliastidlali. Al'urdunu: Markaz Alkitaab Al'akadimi.

Al-Salami, Ali (2016). Alsiyasat al'iidariat fi easr almaelumati. Alqahirata: Dar Alnahdat Alearabiati.

Al-Shammari, Fatima bint Moqbel Salfeeq (2018). Darajat tatbiq mabadi alhawkamat fi alkuliyaat al'ahliat bimadinat Alrayad: Almueawiqat wasubul altatwiri. Majalat Aleulum Altarbawiat bi Jamieat Almalik Saeud, 30(3), 399-426.

Al-Shehri, Abdullah bin Awad (2018). Darajat mumarasat alshafaafiat al'iidariat wamutatalibat tawafuriha fi aljamieat Alsaeudiati. Almajalat Altarbawiat bi Jamieat Suhai, 54, 489-522.

Al-Shehri, Abdullah bin Awad (2020). Alshafaafiat al'iidariat fi almuasasat altaelimiati. Amman, Al'urdunn: Dar Alyazuri Lilnashr Waltawziei. 
خليفة بن محمد الفتحي داوود عبدالملك الحدابي وجيهة ثابت العاني ميراح سعود

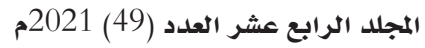

Al-Subaie, Faris Alloush (2011). Dawr alshafaafiat walmusa'alat fi alhadi min alfasad al'iidarii fi alqitaeat alhukumia (Utaruhat dukturah). Jamieat Nayif Alearabiat Lileulum Al'amniati, Alriyad.

Al-Sunaidi, Aisha Sultan (2014). Dawr alhakimiat alrashidat fi tafeil wazayif aljamieat alrayiysiat fi aljamieat aleumanyt: Almueiqat wasubul altatwir (Risalat majistir). Jamieat Alyrmuk, Al'urdun.

Al-Tai, Ali, wa Hamad, Alaa (2010). Abead alhakimiat almahaliyat fi aleiraq: Dirasat maydaniatan fi almajlis almahaliyi liqada' almahmudi. Majalat Kuliyat Baghdad Lileulum Alaiqtisadiati, (25), 41-67.

Al-Tasha, Ghoneim Hamoud (2014). Alshafaafiat al'iidariat ladaa al'iidarat al'akadimiat fi muasasat altaelim aleali alrasmiat fi dawlat alkuayt. Majalat Kuliyat Altarbiat bi Jamieat Eayn Shams, 2(38), 936-975.

Al-Wajeeh, Ahmed Ali Qassem Mohsen (2020). Athar tatbiq maeayir alhawkamat fi taqyim jawdat almurajaeat aldaakhiliat fi aljamieat alyamaniat al'ahliati. Almajalat Alearabiat Lidaman Jawdat Altaelim Aljamieii, 13(46), 81-103.

Alwan, Jaafar Ahmed (2013). Alshafaafiat al'iidariat bayn almafhum waltatbiqi. Majalat Altanmiat Al'iidariati, (102).

Atom, Youmna Ahmed (2013). Darajat mumarasat alshafaafiat fi alqararat al'iidariat min wijhat nazar alqadat al'akadimiiyn wa'aeda' hayyat altadris fi aljamieat Al'urduniyat alrasmiat walkhasati. Majalat Kuliyat Altarbiat bi Jamieat Eayn Shams, 37(1), 735-773.

Badah, Ahmed (2014). Darajat almumarasat alshafaafiat al'iidariat fi aljamieat Al'urduniyat alkhasat min wijhat nazar ruasa' al'aqsam al'akadimiat fiha. Majalat Kuliyat Altarbiat bi Jamieat Al'iiskandariat, 24(2), 23-58.

Fatuma, Makhnath (2020). Dawr alhawkamat fi tatwir 'iidarat al'awqafi: Halat Aljazayir (Utaruhat dukturah). Jamieat Zayaan Eashur, Aljulfata, Aljazayir.

Ghanem, Adnan Kamel (2017). Darajat tatbiq ruasa' al'aqsam alakadimiat lilshafaafiat al'iidariat fi kuliyaat almujtamae alkhasat fi muhafazat eamaan waealaqatiha bialtafawul alakadimi li'aeda' hayyat altadris min wijhat nazarihim (Risalat majistir). Jamieat Alsharq Al'awsat, Al'urdunn.

Hamid, Mohammed Abdullah Hassan (2016). Tatwir al'ada' albahthii liljamieat fi daw' al'iidarat bialqiami. Al'urdun: Dar Ghayda' Lilnashr Waltawziei.

Kandalii, Amer (2019). Manhajiat albahth alealmii. Al'urdunu: Dar Alyazurii Aleilmiat Lilnashr Waltawziei.

Mansour, Nasir Al-Din (2012). Alhawkamat aljayidatu. Al'iiskandiriatu: Dar Aljamieati.

Munazamat Alshafaafiat Alduwlia (2006). Nizam alnazahat alearabii fi muajahat alfasadi. Bayrut: Almarkaz Allubnania Lildirasati. 
Nasser Al-Din, Yacoub Adel (2012). Itar nazariun muqtarah lihawkamat aljamieat wamuashirat tatbiqiha fi daw' mutatalibat aljawdat alshaamilati. Majalat Tatwir Al'ada' Aljamieii, 1(2), 85-103.

Othman, Muhammad Qadri (2014). Alshafaafiat al'iidariatu. Majalat Alfikr Alshurti, 23(90), 165-206.

Othman, Salahuddin Abu Bakr (2017). Waqie mumarasat alshafaafiat al'iidariat fi aljamieat Alsuwdaniat min wijhat nazar alqiadat al'akadimiat wal'iidaria (Utaruhat dukturah). Jamieat Umm Darman Al'iislamiati, Alsuwdan.

Owais, Mohamed Zaki (2012). Thawrat misr wamustaqbal altaelim aleali. Misr: Almaktabat Alakadimiati.

Rabaa'a, Suha Abdel-Wahhab Mohamed, wa Al-Sharman, Munira Mahmoud (2017). Darajat tatbia alhawkamat al'iidariat fi jamieat alyarmuk min wijhat nazar alqadat al'akadimiiyn wa'aeda' hayyat altadrisi: Almueawiqat walhulul almuqtarahati. Aleulum Altarbawiata, 25(3), 468-502.

Saad, Nidaa Akram Ahmed (2018). Alshafaafiat al'iidariat ladaa ruasa al'aqsam al'akadimiat fi aljamieat Al'urduniyat alkhasat fi aleasimat eamaan waealaqatiha bialthiqat altanzimiat li'aeda' hayyat altadris (Risalat majistir), Jamieat Alsharq Al'awsat, Al'urdunn.

Saeed, Shawky Tariq (2019). Muhasabat alsharikati. Al'urdunu: Dar Ghayda' Lilnashr Waltawziei.

Shalaby, Sabri Ahmed (2014). Mabadi alhawkamat watatbiqatuha fi dual mukhtarati: Aldanimark walubnan. Bayrut: Aldaar Alearabiat Lilmusueati.

Taha, Muhammad (2017). Waqie tatbiq maeayir alhawkamat fi Jamieat Eayn Shams bi Misr (Risalat majistir). Jamieat Eayn Shams, Misr.

Taib, Aziza bint Abdullah bin Abdul Rahman (2018). Dirasat tahliliat limafhum alhawkamat alrashidat wamutatalibat tatbiqiha fi aliamieat Alsaeudiati. Aleulum Altarbawiata, 26(2), 184-227.

Wizarat Altaelim Aleali (2020). Dalil altarkhis almuasisii: Dawabit wa'iijra'atun. Saltanat Oman. Aistariie bitarikh Yanayir 9, 2020, min https://bit.ly/3HrvKbs

Wizarat Altaelim Aleali (2021). Albaramij alakadimiat bimuasasat altaelim aleali alkhasati. Saltanat Oman. Aistarjie bitarikh Yuliu 11, 2020, min https://bit.ly/3ngP3Mv 